\title{
Electron transfer at the mineral/water interface: Selenium reduction by ferrous iron sorbed on clay
}

\author{
L. Charlet $^{1 *}$, A.C. Scheinost ${ }^{2}$, C. Tournassat ${ }^{3}$, J.M. Greneche ${ }^{4}$,
} A. Géhin ${ }^{1}$, A. Fernández-Martínez ${ }^{1,5}$, S. Coudert ${ }^{1}$, D. Tisserand ${ }^{1}$, J. Brendle $^{6}$

${ }^{1}$ Environmental Geochemistry Group, LGIT-OSUG, Grenoble University, 38041 Grenoble, Cedex 9, France

${ }^{2}$ Rossendorf Beamline at ESRF, Grenoble, France, and Institute of Radiochemistry, FZR, Dresden, Germany

${ }^{3}$ BRGM, Environment and Process Division, 3 avenue Claude Guillemin, F-45060 Orléans

Cedex 2, France

${ }^{4}$ Laboratoire de Physique de l'Etat Condensé UMR CNRS 6087, Université du Maine, F-72085

Le Mans, Cedex 9, France

${ }^{5}$ Institut Laue-Langevin, 6 rue Jules Horowitz, 38042 Grenoble Cedex 9, France

${ }^{6}$ Laboratoire de Matériaux à Porosité Contrôlée, UMR CNRS 7016, Ecole Nationale Supérieure de Chimie de Mulhouse, Université de Haute Alsace, 3 rue A. Werner, F-68093 Mulhouse, France

\footnotetext{
*Corresponding author

Phone: +33476828020

Fax: +33476828101
}

E-mail: Laurent.charlet@,obs.ujf-grenoble.fr 
Abstract- The mobility and availability of the toxic metalloid selenium in the environment is largely controlled by sorption and redox reactions, which may proceed at temporal scales similar to that of subsurface water movement under saturated or unsaturated conditions. Since such waters are often anaerobic and rich in $\mathrm{Fe}^{2+}$, we investigated the long-term ( $\leq 1$ month) kinetics of selenite $\left(\mathrm{Se}\left(\mathrm{IV} \mathrm{O}_{3}{ }^{-}\right)\right.$sorption to montmorillonite in the presence of $\mathrm{Fe}^{2+}$ under anoxic conditions. A synthetic montmorillonite was used to eliminate the influence of structural Fe. In the absence of aqueous $\mathrm{Fe}^{2+}$, selenite was sorbed as outer-sphere sorption complex, covering only part of the positive edge sites, as verified by a structure-based MUSIC model and Se K-edge XAS (X-ray absorption spectroscopy). When selenite was added to montmorillonite previously equilibrated with $\mathrm{Fe}^{2+}$ solution however, slow reduction of Se and formation of a solid phase was observed with Se K-edge XANES (x-ray absorption near-edge spectroscopy) and EXAFS (extended x-ray absorption finestructure) spectroscopy. Iterative transformation factor analysis of XANES and EXAFS spectra suggested that only one Se reaction product formed, which was identified as nano-particulate $\operatorname{Se}(0)$. Even after one month, only $75 \%$ of the initially sorbed Se(IV) was reduced to this solid species. Mössbauer spectrometry revealed that before and after addition and reduction of Se, $5 \%$ of total sorbed Fe occurred as $\mathrm{Fe}(\mathrm{III})$ species on edge sites of montmorillonite $\left(\approx 2 \mathrm{mmol} \mathrm{kg}^{-1}\right)$. The only change observed after addition of Se was the formation of a new Fe(II) species (15\%) attributed to the formation of an outer-sphere Fe(II)-Se sorption complex. The combined Mössbauer and XAS results hence clearly suggest that the Se and Fe redox reactions are not directly coupled. Based on the results of a companion paper, we hypothesize that the electrons produced in the absence of Se by oxidation of sorbed $\mathrm{Fe}(\mathrm{II})$ are stored, for example by formation of surface $\mathrm{H}_{2}$ species, and are then 
available for the later Se(IV) reduction. The slow reaction rate indicates a diffusion controlled process. Homogeneous precipitation of an iron selenite was thermodynamically predicted and experimentally observed only in the absence of clay. Interestingly, half of Fe was oxidized in this precipitate (Mössbauer). Since DFT calculations predicted the oxidation of $\mathrm{Fe}$ at the water-FeSe solid interface only and not in the bulk phase, the average particle size of this precipitate does not exceed 2 nm. A comparison with the Mössbauer and XAS spectra of the clay samples demonstrates that such homogenous precipitation can be excluded as a mechanism for the observed slow Se reduction, emphasizing the role of abiotic, heterogeneous precipitation and reduction for the removal of Se from subsurface waters. 


\section{INTRODUCTION}

\subsection{The environmental problem}

Selenium is a trace element, essential to the human body. As opposed to many other trace elements however, the optimal daily uptake is very narrow and slight differences in daily uptake may lead to either toxicity (selenosis) or deficiency. Countries with a chronic selenium deficit, such as France or Finland, have implemented a program of field fertilization with selenium-doped nitrates, but the very success of these programs depends on the efficient bioavailability of soil selenium to crops. For instance, outbreaks of the Keshan deficiency disease, a type of heart disease, in China are restricted to well defined geographic regions (Fordyce, 2005) where soils unexpectedly have rather significant total concentrations in selenium (13 to $160 \mu \mathrm{g} / \mathrm{g}$ soil, Tan, 1994). Moreover, no significant correlation between the disease prevalence and the total soil selenium content could be established (Johnson et al., 2000). Crops grown in the region are thus unable to extract selenium from these soils, which are also high in organic matter, and this low bioavailability is attributed either to reduction of selenium to strongly adsorbed or poorly soluble forms (Hartikainen, 2005) or to selenium strongly bound to organic fractions (Johnson et al., 2000; Wen et al. 2006). The bioavailability of selenium is therefore highly dependant on local reducing conditions, such as the ones present in organic matter rich soil aggregates, and thus on the local selenium valence state (e.g., $+6,+4,0,-1,-2)$. The same concept applies to the deep anoxic clay rich systems

considered for the disposal of nuclear waste. In these systems, very rich in $\mathrm{Fe}^{2+}$ due to the corrosion of containers and steel structure elements, the speciation of the 
radioactive ${ }^{79} \mathrm{Se}$, an important ${ }^{235} \mathrm{U}$ fission product, is also of concern. Depending on whether present as an oxyanion or as a reduced species, the selenium mobility in nuclear waste disposal systems will be drastically different (ANDRA 2005; SKB 2006).

The $\mathrm{Se}(\mathrm{VI})$ valence state is stable in oxic environments and exists as the selenate $\left(\mathrm{SeO}_{4}{ }^{2-}\right)$ anion, which is weakly sorbed by mineral materials and generally soluble. As a consequence, $\mathrm{Se}(\mathrm{VI})$ shows high bioavailability to crops and fish and high mobility in soils and groundwater. For instance, irrigation of Se-rich soils led to high levels of Se in drainage waters (up to $3700 \mu \mathrm{g} / \mathrm{L}$ ), which caused a large-scale intoxication of the wildlife in the Kesterson National Wildlife refuge in California (USA) in the 1980s (Deverel and Fujii, 1988). Earlier work suggested that Se(VI) behaves like sulfate, with low sorption and high mobility (BALISTRIERI and CHAO, 1990; Goldberg and Traina, 1987; Hayes et al., 1987; Neal and Sposito, 1989). More recent work has demonstrated the formation of $\mathrm{Se}(\mathrm{VI})$ inner-sphere sorption complexes by XAS and IR spectroscopies and electrophoretic mobility measurements (Manceau and Charlet, 1994; Su and Suarez, 2000). Both outer-sphere and innersphere sorption complexes may in fact occur simultaneously, the partitioning between both species being controlled by $\mathrm{pH}$, ionic strength and mineral surface properties (PEAK and SpARKS, 2002), such as the presence of specific surface sites on different Fe oxides (MANCEAU and CHARLET, 1994).

\subsection{Speciation of selenium in reductive environments}

Tetravalent $\mathrm{Se}[\mathrm{Se}(\mathrm{IV})]$ is the stable valence state under mildly reducing or anoxic condition $\left(0.26 \mathrm{~V}<\mathrm{Eh}<0.55 \mathrm{~V}\right.$ at $\mathrm{pH} 7$ and $1 \mu \mathrm{mol} \mathrm{L} \mathrm{L}^{-1}$ total concentration; White et al., 1991). It exists as the selenite $\left(\mathrm{SeO}_{3}{ }^{2-}\right)$ anion, which is more strongly 
bound to mineral surfaces (e.g. Fe and Mn oxides) (BALISTRIERI and CHAO, 1990; HAYES et al., 1989). Earlier investigations suggested that Se(IV) behaves like phosphate, forming strong inner-sphere sorption complexes (BARROW and WHELAN, 1989; NeAl et al., 1987a; NeAL et al., 1987b; ZhANG and SPARKS, 1990) and substituting for phosphate in apatite (DUC et al., 2003; MONTEIL-RIVERA et al., 2000). In reducing sediments, $\mathrm{Se}(\mathrm{IV})$ and $\mathrm{Se}(\mathrm{VI})$ are converted to $\mathrm{Se}(0)$ and reduced $\mathrm{Se}$ species (oxidation states -1 and -2 ). The process is thought to proceed via sorption to Fe and Mn oxides, reductive dissolution of the latter minerals, mineralization of organic matter and precipitation as $\mathrm{Se}(0)$, ferroselite and Se-hosting pyrite (BELZILE et al., 2000; TOKUnAga et al., 1997; Velinsky and CUTter, 1990; Velinsky and CUTTER, 1991). Indeed, ferroselite-pyrite associates prevail in ore deposits (HATTENHOWARD, 1977; XIONG, 2003). The reduction may also involve the reduction by $\mathrm{HS}^{-}$, pyrite and organic matter, as in Bloom clay (BRUGGEMAN et al., 2006), and it may be either microbial or inorganic. Microbial reduction of $\mathrm{Se}(\mathrm{IV})$ and $\mathrm{Se}(\mathrm{VI})$ to $\operatorname{Se}(0)$ has been confirmed by several laboratory studies (GARBISU et al., 1996;

Oremland et al., 1989; Oremland and Steinberg, 1990; Zhang and Moore, 1997). Abiotic reduction of $\operatorname{Se}(\mathrm{VI})$ to $\operatorname{Se}(0)$ has only been reported to date by the $\mathrm{Fe}(\mathrm{II}) / \mathrm{Fe}(\mathrm{III})$ mineral green rust (MYNENI et al., 1997). However, green rust minerals have rarely been observed in natural environments due to their meta-stability with respect to magnetite and siderite. In contrast, Fe(II)-clay systems are much more frequent in anoxic environments and may act as potential reductants of Se.

\subsection{The reactive $\mathrm{Fe}(\mathrm{II})$-clay system}

Montmorillonite is a 2:1 layer-type smectite clay mineral found in a variety of environments. It has two reactive surfaces: the siloxane basal planes, and the edges 
with mixed aluminol and silanol groups. $\mathrm{Fe}^{2+}$ sorbs to these siloxane planes by cation exchange (CHARLET and TOURnASSAT, 2005; KAMEI et al., 1999). It also sorbs to the edges via a complex pH-dependent surface complexation mechanism (Géhin et al., 2007). The sorption sites for metal ions such as $\mathrm{Fe}^{2+}$ can be considered as a combination of the 27 reactive edge sites distinguished for proton adsorption based on the structure and composition of an ideal montmorillonite structure with $\mathrm{Mg}$ and $\mathrm{Fe}$ (ferrous and ferric) octahedral substitutions but with no tetrahedral substitution (Fig. 1). Out of the 27 sites, five main sites are quantitatively sufficient to describe the titration curves of natural montmorillonite (Tournassat et al., 2004b, 2004c). $\mathrm{Fe}^{2+}$ specific adsorption occurs at $\mathrm{pH}$ values as low as $\mathrm{pH} 2$ or 3 , depending on the montmorillonite sample, and this behavior demonstrates the extreme high affinity of clay edge site(s) for the $\mathrm{Fe}^{2+}$ ion in addition to cation exchange sites (Géhin et al., 2007). The use of the ${ }^{57} \mathrm{Fe}$ isotope and Mössbauer spectroscopy has been instrumental in distinguishing adsorbed $\mathrm{Fe}^{2+}$ from structural iron (III) (SILVESTER et al., 2005; WILLIAMS and M., 2004). ${ }^{57} \mathrm{Fe}$ was used to quantify the $\mathrm{Fe}(\mathrm{III}) / \mathrm{Fe}(\mathrm{II})$ ratio of sorbed iron (Géhin et al., 2007). At pH values where a pre-sorption edge plateau occurs $(2<$ $\mathrm{pH}<7.5$ ), the ratio increases from 0.14 at $\mathrm{pH} 2$ up to 0.74 at $\mathrm{pH} 7$. As $\mathrm{pH}$ increases and protons are removed from the clay edge surface, more highly reactive edge sites acquire a steric configuration that stabilizes $\mathrm{Fe}(\mathrm{III})$ relative to $\mathrm{Fe}(\mathrm{II})$. This surface oxidation of $\mathrm{Fe}(\mathrm{II})$ is completely reversible, i.e. by lowering the suspension $\mathrm{pH}$, the $\mathrm{Fe}(\mathrm{II}) / \mathrm{Fe}(\mathrm{III})$ ratio is again reduced to the value observed before raising the $\mathrm{pH}$. Therefore the oxidation agent is water and the hydrogen molecules produced by the reaction remain in the vicinity of the surface complex for the reaction to be macroscopically reversible. 


\subsection{Aims of the present study}

With this background, we investigated the long-term kinetics of Se(IV) reduction in $\mathrm{Fe}^{2+}$-montmorillonite suspensions, employing a strictly $\mathrm{Fe}$-free montmorillonite. We coupled two spectroscopic techniques, Mössbauer spectroscopy and X-ray absorption spectroscopy, to explore the mechanism and reduction kinetics in the $\mathrm{Fe} 2+/ \mathrm{Se} 4+/$ montmorillonite system as an analogue of many $\mathrm{O}_{2}$-free soil and groundwater systems where the transport of selenium is of concern. Mössbauer was not only used to quantify the $\mathrm{Fe}(\mathrm{II}) / \mathrm{Fe}(\mathrm{III})$ ratio in each system but also to distinguish different species in each oxidation state. Selenium K-edge X-ray Near-Edge spectroscopy (XANES) and Extended X-ray Absorption Fine-Structure (EXAFS) spectroscopy, evaluated by Iterative Transformation Factor Analysis (ITFA) were used to derive the number of different oxidation states, to identify the local structure of the species and to quantify their relative amounts. Molecular Dynamics calculations and a bond valence approach were used to investigate the oxidation state and structure of hydrated Fe selenite surfaces as reference model. 


\section{MATERIAL AND METHODS}

The present study relies on the combination of a large panel of experimental and modeling approaches. Chemical conditions and modeling with regards to Fe(II) sorption onto the synthetic montmorillonite used in this study have been described in a previous paper (Géhin et al. 2007). The effect of this sorbed $\mathrm{Fe}(\mathrm{II})$ on the Se speciation is investigated here through Se sorption kinetics where $\mathrm{pH}$, Eh and Se and Fe concentrations variations were monitored. During the course of these experiments, solid samples were taken in order to perform spectroscopic measurements: XANES/EXAFS and Mössbauer spectrometry for Se and Fe speciation on the solid, respectively. The coherence between the results from all of these techniques was checked through the application of solution/solid speciation models for Se and Fe. Finally, Density Functional Theory studies were performed to verify the reliability of some features of our interpretations.

\subsection{Laboratory material and methods}

\subsubsection{Chemicals}

All solutions and suspensions were prepared with boiled, argon-degassed Millipore Milli-Q $18 \mathrm{M} \Omega$ water. $\mathrm{NaOH}$ and $\mathrm{HCl}$ stock solutions were made from Titrisol ampoules. $\mathrm{CaCl}_{2}$ and $\mathrm{FeCl}_{2}$ stock solutions were prepared from analytical grade salt. HPLC-AFS speciation analysis of Se(IV) stock solution kept in contact with air showed a slow but distinct oxidation of $\mathrm{Se}(\mathrm{IV})$ to $\mathrm{Se}(\mathrm{VI})$, hence the $\mathrm{Se}(\mathrm{IV})$ stock solutions were prepared with degassed deionized water and kept in a glove box with inert gas. ${ }^{57} \mathrm{Fe}$ stock solution was prepared by dissolving $100 \mathrm{mg}$ of ${ }^{57} \mathrm{Fe}(0)$ in concentrated $\mathrm{HCl}\left(0.1 \mathrm{~mol} \mathrm{~L}^{-1}\right)$ at $\sim 100^{\circ} \mathrm{C}$. The dissolved ${ }^{57} \mathrm{Fe}(\mathrm{II})$ was then transferred into the glove box and diluted in deionized water to obtain a $1000 \mathrm{ppm}{ }^{57} \mathrm{Fe}$ (II) stock 
solution. The very acidic conditions prevented the oxidation of the suspension prior to its transfer to the glove box.

\subsubsection{Clay minerals}

A synthetic montmorillonite sample was prepared according to Reinholdt et al. (2001). Ca-montmorillonite was obtained by repeated saturation of the prepared Namontmorillonite with a $0.05 \mathrm{~mol} \mathrm{~L}-1$ aqueous solution of $\mathrm{CaCl}_{2}$. The clay suspension was then argon-degassed and transferred into the glove box (see Géhin et al., 2007). The sample has the theoretical formula:

$$
\mathrm{Ca}_{0.15}\left[\left(\mathrm{Al}_{1.70} \mathrm{Mg}_{0.30}\right) \mathrm{Si}_{4} \mathrm{O}_{10}(\mathrm{OH}, \mathrm{F})_{2}\right], \mathrm{n} \mathrm{H}_{2} \mathrm{O}
$$

where represents the vacant site in the octahedral layer of this dioctahedral smectite. It includes two particle sizes, one with average dimensions of 200-250 nm long/120 $\mathrm{nm}$ wide and the second one $50 \mathrm{~nm}$ long/25 nm wide (Cadene et al., 2005). The X-ray diffraction pattern of the sample was similar to Ca-saturated, purified natural MX80 Wyoming bentonite (see Géhin et al., 2007).

The cation exchange capacity of the synthetic montmorillonite was measured with the Cs-Li method (Anderson and Sposito, 1991). At pH 7.0, the permanent structural charge (Cs) was $0.44 \mathrm{eq} / \mathrm{kg}$ and the variable charge ( $\mathrm{Li})$ was $0.19 \mathrm{eq} / \mathrm{kg}$, accounting for a total CEC of $0.63 \mathrm{eq} / \mathrm{kg}$. The methods used to determine the concentration of the clay suspension are available from Tournassat et al. (2004c).

\subsubsection{Oxygen control}

All experiments were conducted at room temperature $\left(25 \pm 2{ }^{\circ} \mathrm{C}\right)$ in a glove box (Jacomex) with a $\mathrm{N}_{2}$ atmosphere. The oxygen partial pressure $\left(\mathrm{pO}_{2}\right)$ was monitored continuously by a Jacomex $\mathrm{O}_{2}$ sensor, and never exceeded 1 ppm. As discussed in detail in a companion paper (Géhin et al., 2007), the rate of $\mathrm{Fe}(\mathrm{II})$ oxidation was 
negligible under the present experimental conditions, where every precaution was taken to minimize the presence of oxygen in solution.

Extreme care was also taken to prevent sample oxidation during the transport from the glove box to the spectroscopy facilities. Small aliquots (a few ml) of suspensions were filtered (Millipore filter $0.022 \mu \mathrm{m}$ ) and the wet pastes were then transferred to Mössbauer or XAS sample holders. The sample holders were sealed with Kapton tape (XAS spectroscopy) or with epoxy resin (Mössbauer spectroscopy) and placed in small plastic boxes. All these steps were performed in the glove box. The samples were then immediately shock-frozen with liquid $\mathrm{N}_{2}$ and transported to the spectroscopic facilities in a Dewar flask filled with liquid $\mathrm{N}_{2}$. At the synchrotron facility, they were transferred within 2 minutes from the Dewar to a closed-cycle $\mathrm{He}$ cryostat with $\mathrm{He}$ atmosphere and $15 \mathrm{~K}$ temperature, which was used for the XAS measurements. At the Mössbauer facility, the samples were transferred within 1 minute from the Dewar to the Mössbauer bath cryostat with a He gas atmosphere. 


\subsubsection{Analyses}

Inductively coupled plasma optical emission spectroscopy (ICP-AES) (Perkin Elmer Optima 3000DV) was used to measure total iron and selenium concentrations above $0.5 \mu \mathrm{mol} \mathrm{L} \mathrm{L}^{-1} \mathrm{Fe}$ and $7.5 \mu \mathrm{mol} \mathrm{L} \mathrm{L}^{-1}$ Se. Total Se concentrations lower than 1.5 $\mu \mathrm{M}$ were analyzed by Atomic Fluorescence Spectrometry (Millenium AFS). The Ferrozine method (Viollier et al., 2000) was also used to measure Fe(II) and Fe(III) separately for concentrations up to $30 \mu \mathrm{M}$ after dilution and to show that no oxidation of $\mathrm{Fe}(\mathrm{II})$ to $\mathrm{Fe}$ (III) had occurred in solution, i.e. that $\mathrm{Fe}^{2+}$ concentration is equal, within measurement accuracy, to Fe total concentration.

\subsection{Wet chemistry and spectrometric investigations}

\subsubsection{Kinetic redox experiments}

$\mathrm{Fe}(\mathrm{II})-\mathrm{Se}(\mathrm{IV})$ redox kinetics in the presence of synthetic montmorillonite was studied in a closed reactor in free $\mathrm{pH}$ drift mode. The $\mathrm{pH}$ of the suspensions was measured in the supernatant with a $\mathrm{pH}$ meter (Metrohm $781 \mathrm{pH} / \mathrm{Ion}$ Meter). The montmorillonite was stored in $0.05 \mathrm{M} \mathrm{CaCl}_{2}$ solution in order to avoid artefacts due to hydration after freeze drying. All the experiments were performed using the same clay stock suspension and were conducted at room temperature with $0.05 \mathrm{M} \mathrm{CaCl}_{2}$ background electrolyte to minimize the $\mathrm{Ca}^{2+}-$ by- $\mathrm{Fe}^{2+}$ exchange in the montmorillonite interlayer by mass effect. The clay concentration of the suspension was set to $20 \mathrm{~g} / \mathrm{L}$ for all the experiments.

The montmorillonite suspension was equilibrated in a $350 \mathrm{ml}$ glass reactor, wrapped with aluminum foil to avoid exposure to light, for one week at $\mathrm{pH} 6.0$ with 5 $\mathrm{mM}$ aqueous ${ }^{57} \mathrm{Fe}^{2+}$ (or for the XAS sample, with regular $\mathrm{Fe}^{2+}$ ) before adding Se. Isotopically pure ${ }^{57} \mathrm{Fe}(\mathrm{II})(>97 \%)$ was used in order to enhance the Mössbauer signal. 
The reactor had three inputs, one for the $\mathrm{pH}$ electrode and two others for adding and retrieving solutions. At time zero an aliquot of a Se(IV) stock solution was introduced in the reactor to obtain an initial solution concentration of $0.5 \mathrm{mM}$. The $\mathrm{pH}$ of the suspension increased up to $\mathrm{pH}$ 7.2. After given reaction periods, a $10 \mathrm{ml}$ sample of suspension was filtered through a $0.22 \mu \mathrm{m}$ pore size membrane and analyzed for selenium concentration. Solutions filtered with smaller pore size membranes $(0.1 \mu \mathrm{m})$ had the same Fe and Se concentration. This indicates that the reacted solid (wet slurry) retained all possibly formed nanoparticles. It was transferred to the respective sample holders for XAS and Mössbauer spectroscopies. The experiment was repeated, but with an initial $\mathrm{pH}$ of 7.6 instead of 7.2 , to follow the pe-pH relationship

\subsection{2 ${ }^{57}$ Fe Mössbauer spectroscopy}

The Mössbauer spectrometer was operated in transmission geometry in constantacceleration mode. The velocity was calibrated against a standard Mössbauer metallic Fe foil at room temperature (RT, $295 \mathrm{~K}$ ). The values of isomer shifts (IS) are reported relative to the $\alpha$-Fe spectrum obtained at RT.

The spectra were fitted with MOSFIT using a discrete number of independent components (single line, quadrupole doublet and magnetic sextet) composed of Lorentzian lines. The line width at half-height $\Gamma\left(\mathrm{mm} \mathrm{s}^{-1}\right)$, the center shift $\delta\left(\mathrm{mm} \mathrm{s}^{-1}\right)$ and the quadrupole splitting $\Delta E_{Q}\left(\mathrm{~mm} \mathrm{~s}^{-1}\right)$ were refined using a least-squared fitting procedure. Standard deviations of parameters were generally less than $0.02 \mathrm{~mm} / \mathrm{s}$ for IS and $\Delta \mathrm{E}_{\mathrm{Q}}, 0.02 \mathrm{~mm} / \mathrm{s}$ for $\Gamma$ and about $1 \%$ for relative absorption area. For a doublet component, the two peaks were assigned with equal areas, in agreement with isotropic powdered samples, i.e. a random distribution of crystallites. 
Spectral Mössbauer analysis can resolve the number of Fe sites, their valence states and the type of magnetic order, through the electric and magnetic hyperfine

interactions at ${ }^{57} \mathrm{Fe}$ nuclei. In the present study, the Mössbauer spectra exhibit quadrupolar structure where the doublet peak separation is known as "quadrupole splitting" and may be designated $\Delta \mathrm{E}_{\mathrm{Q}}$ while the center of each component is related to the "isomer shift", which is sensitive to the s electron density, i.e. the valence state. The method consequently enables the presence of $\mathrm{Fe}(\mathrm{II}), \mathrm{Fe}(\mathrm{III})$ and intermediate or mixed valence states, i.e. with localized and delocalized electrons, respectively to be established. When the hyperfine parameters are well refined, both IS and $\Delta \mathrm{E}_{\mathrm{Q}}$ serve as a fingerprint in identifying the particular mineral phase or species.

For well-crystallized materials, the typical measured peak width $\Gamma$ is $0.3-0.35$. Line broadening may be attributed to either (1) an amorphous nature of the material; or (2) a lack of crystallinity (presence of atomic defects as substitution vacancies); or (3) the occurrence of superparamagnetic fluctuations originating from the presence of small magnetic particles $(<20-30 \mathrm{~nm})$, when the interactions between particles are weak.

\subsubsection{X-ray absorption spectroscopy}

Selenium K-edge XAS spectra were collected at the Rossendorf Beamline (BM20) at the ESRF. Both the X-ray Absorption Near-Edge Spectroscopy (XANES) region around the absorption edge and the Extended X-ray Absorption Fine Structure (EXAFS) region above the absorption edge were recorded. A Si(111) double crystal monochromator (DCM) was used with electronic beam flux stabilization (MOSTAB) through a fast feedback loop between the pitch movement of the $2^{\text {nd }}$ crystal and the output signal from the $\mathrm{I}_{0}$ ion chamber. The energy of the DCM was calibrated relative 
to the Au K-edge of metallic gold $(11919 \mathrm{eV})$. Collimation, vertical focusing and the suppression of higher-order harmonics was achieved with two Pt-coated cylindrical mirrors before and after the DCM.

The samples were measured in fluorescence mode using a 13-element $\mathrm{Ge}$ detector (Canberra) with digital signal processing (XIA DXP-2X4T-M). A lowvibration, closed-cycle $\mathrm{He}$ cryostat (CryoVac) cooled the samples to $15 \mathrm{~K}$ and excluded $\mathrm{O}_{2}$ from the sample environment, thereby suppressing sample redox processes due to $\mathrm{O}_{2}$ diffusion and photoreduction and improving spectral quality due to reduction of the thermal contributions to the Debye-Waller factors. Several scans were combined for improved signal quality. The energy of each scan was corrected using a simultaneously monitored $\operatorname{Au}(0)$ foil and the dead time of the fluorescence detector was corrected by employing the nonlinear relation between the count rates of SCA, $r$, and ICR: $\rho r=\kappa \rho \exp (-\rho \tau)$, with the deadtime ( $\mu$ sec), $\tau$, and the proportionality constant, $\kappa$ (SixPack, http://www.stanford.edu/ $\sim$ swebb) $)$.

Quantitative speciation was performed by applying Iterative Transformation Factor Analysis (ITFA) to the normalized XANES spectra and to the $\mathrm{k}^{3}$-weighted chi spectra (Rossberg et al., 2003). This method combines principal component analysis (PCA) and iterative target test (ITT) to derive real spectra of endmember species and their relative contribution to each sample spectrum, i.e. the full quantitative speciation. The advantage in relation to standard methods (PCA followed by target test and linear combination fit in separate steps) is the higher reliability and the possibility of extracting the real spectra of endmember species, even in the absence of appropriate reference spectra.

To determine the short-range structure of extracted species, EXAFS shell fitting was performed using FEFF 7 and WinXAS (Ankudinov and Rehr, 1997; 
Ressler, 1998). Based on the fits of reference minerals, the error of the first shell coordination numbers is better than $\pm 25 \%$, and the error of distances is $\pm 0.01 \AA$.

As reference minerals were available a natural achavalite sample, nominally $\mathrm{Fe}^{\mathrm{II}} \mathrm{Se}$, from Cerro de Cachenta, Mendoza (Argentina); the EXAFS range of this sample was restricted to $10 \AA^{-1}$ because of a high $\mathrm{Pb}$ content. A synthetic $\mathrm{Fe}^{\mathrm{II}} \mathrm{Se}$ sample (AlfaAesar) consisted predominately of tetragonal $\mathrm{Fe}^{\mathrm{II}} \mathrm{Se}$, in addition to minor amounts of hexagonal $\mathrm{Fe}^{\mathrm{II}} \mathrm{Se}$ (achavalite) and hexagonal $\mathrm{Se}(0)$ as confirmed by XRD collected under an $\mathrm{O}_{2}$-free atmosphere. The XAS spectrum of ferroselite, orthorhombic $\mathrm{Fe}^{\mathrm{II}} \mathrm{Se}_{2}$, was provided by Dan Strawn, University of Idaho. A sample of trigonal, grey $\mathrm{Se}(0)$ was obtained from the School of Mines Mineralogy Museum, Paris. As solid $\mathrm{Se}(\mathrm{IV})$ reference, $\mathrm{Na}_{2} \mathrm{SeO}_{3} 5 \mathrm{H}_{2} \mathrm{O}$ purchased from Merck was used. Finally, an $\mathrm{FeSeO}_{3}$ precipitate was obtained by reacting $50 \mathrm{mM} \mathrm{Se}(\mathrm{IV})$ with $50 \mathrm{mM}$ $\mathrm{Fe}^{2+}$ at $\mathrm{pH}$ 5. The precipitate was filtered after $4 \mathrm{~h}$, and repeatedly washed with deionized water. The XANES and EXAFS spectra of these references are shown in Figs. 2, 8 and 10 .

\subsection{Modeling approaches}

\subsubsection{Bond Valence Model}

The solid compound $\mathrm{FeSeO}_{3}$ was studied by Density Functional Theory (DFT) based Molecular Dynamics (MD) simulations, using the Vienna Ab-initio Simulation Package (VASP) (Kresse and Hafner, 1993). Details of the calculations can be found elsewhere (Cuello et al., 2007). Mulliken Population Analyses have been performed with DMol3 (Delley, 1990) in order to study the optimized structure of the bulk of 
$\mathrm{FeSeO}_{3}$. A Double Numerical plus Polarization (DNP) set (Delley, 1990) has been used as basis set for the atomic orbitals. The Perdew-Burke-Ernzerhof exchange correlation functional (Perdew et al., 1996) has been used to calculate the exchangecorrelation energy. These calculations project the charge density into the numerical basis set of atomic orbitals, which gives a value for bond populations (order) and atomic charge.

The results of the simulations have been interpreted in terms of the $2^{\text {nd }}$ Pauling's rule of electrostatic valence (Pauling, 1929). It states that the total strength of the valence bonds that reach an ion from all neighboring atoms is equal to the charge of the ion $\left(V_{i}\right)$ :

$$
V_{i}=\sum_{j} s_{i j}
$$

where $V_{i}$ is the charge of the $i$ ion and $s_{i j}$ is the strength of the bond between a neighboring $j$ atom and the $i$ ion. The more commonly used model for the calculation of the bond strength is that from Brown and Altermatt (Brown and Altermatt, 1985) that relates $s_{i j}$ to the bond lengths by this expression:

$$
S_{i j}=\exp \left[\left(R_{0}-R_{i j}\right) / b\right]
$$

with $R_{i j}$ is the bond length between the atoms and $R_{0}$ and $b$ are parameters fitted by analyzing several known structures.

The Bond Valence approach is implemented into the MUSIC model for surface complexation in order to predict proton affinity constants based on structural parameters (Hiemstra et al., 1989a; Hiemstra et al., 1989b; Hiemstra et al., 1996).

\subsubsection{MUSIC surface complexation model and Fe sorption model}


The clay MUSIC model of Tournassat et al. (2004c) is a non-electrostatic model, as previously developed by (Baeyens and Bradbury, 1997), which aims at integrating the complexity of the edge sites in both structural and chemical terms. The MUSIC approach (Hiemstra et al., 1989a; Hiemstra et al., 1989b; Hiemstra et al., 1996) has been used to obtain the protonation/deprotonation $\mathrm{pK}$ of the edge sites. At $\mathrm{pH}$ values below 7-8, this model suggested that two main sites control the change in positive edge charge due to their relative amount and $\mathrm{pK}$ :

$$
\begin{array}{lr}
\mathrm{Si}-\mathrm{O}^{-1 / 2}-\mathrm{Al}+\mathrm{H}^{+} \Leftrightarrow \mathrm{Si}-\mathrm{OH}^{+1 / 2}-\mathrm{Al} & \log \mathrm{K}_{1}=-7.2 \\
\mathrm{Al}-\mathrm{OH}-\mathrm{Al}+\mathrm{H}^{+} \Leftrightarrow \mathrm{Al}-\mathrm{OH}_{2}^{+1}-\mathrm{Al} & \log \mathrm{K}_{2}=-4.8
\end{array}
$$

Acid-base and complexation reactions occurring both at edge sites and at cation exchange sites were used, as in the earlier Baeyens and Bradbury model. Due to the large variety of different edge sites, some edge sites were grouped together in the model and some sites were neglected due to their low density at the edges. Despite the numerous approximations relative to the contribution of different edge faces and thus to the different edge surface group populations, the MUSIC approach successfully described the surface proton charge of montmorillonite and the apparent CEC variations as a function of $\mathrm{pH}$ (Tournassat et al., 2004c). This model was tested for the prediction of Se adsorption as a function of $\mathrm{pH}$. The sorption of Fe was not modeled using the MUSIC approach mainly because it is still not possible to attribute the sorption behavior of Fe to specific chemical-structural sites. Therefore, we used a simple specific sorption model for Fe as described in the companion paper (Géhin et al., 2007). 


\section{RESULTS AND DISCUSSION}

\subsection{Adsorption of single ions $\left(\mathrm{SeO}_{3}{ }^{2-}\right.$ or $\left.\mathrm{Fe}^{2+}\right)$ on clay edges}

Adsorption of selenium oxyanions on clays is generally considered to be very low and to be affected to a greater extent by $\mathrm{pH}$ than by layer type minerals, although the 2:1 mineral montmorillonite exhibits smaller sorption capacity than the $1: 1$ mineral kaolinite (Bar-Yosef and Meek, 1987). The permanent negative electric field near the surface of montmorillonite is more effective in screening the positive charge of clay edges (TOURNASSAT et al., 2004c), thus restricting anion accessibility to the edge adsorption sites (Avena, 2002; BAR-Yosef and MeEK, 1987; CHAng and SPOSITO, 1996). Depending on whether the electric edge surface potential is explicitly taken into account or not, montmorillonite PZNPC varies from $\mathrm{pH} 4.5$ (Bourg and Sposito, 2007) to pH 7.3 (Tournassat et al., 2004b), and the presence of positively charged edge sites varies accordingly.

The EXAFS spectrum of the Se(IV) reacted montmorillonite in the absence of $\mathrm{Fe}^{2+}$ (Fig. 2) was used to determine the structure of the sorption complex. The fit shows only one oxygen coordination shell, with the fitted values close to the expected coordination number of three and an average distance of $1.70 \AA$, in line with the species $\mathrm{Se}_{3}{ }^{2-}$. In spite of the long $\mathrm{k}$ range $(2-14 \AA-\&)$ and the measurement at $15 \mathrm{~K}$, which suppresses thermal atomic vibrations, no further atomic shell beyond the $\mathrm{O}$ coordination sphere was detected. Therefore we can exclude the presence of more than $5 \%$ of inner-sphere complexes. Hence, on synthetic montmorillonite at $\mathrm{pH} 6.0$, outer-sphere selenite sorption prevails, presumably to positively charged edge sites. 
This result is in contrast to that of Peak et al. (2006), who observed prevalently inner-sphere sorption of selenite to a natural montmorillonite. While their interpretation based on EXAFS data may be biased by a short $\mathrm{k}$ range and higher noise level, their careful interpretation of the XANES region provides compelling evidence for the prevalence of inner-sphere complexes. By comparison, the XANES of our sample of selenite sorbed to montmorillonite (Fig. 2 left, orange) is clearly different, being more similar to the structures with delocalized Se-O double bonds (e.g. $\mathrm{SeO}_{3}{ }^{2-}$ and $\mathrm{HSeO}_{3}{ }^{-}$) than to the structure with a localized double bond (e.g. $\mathrm{H}_{2} \mathrm{SeO}_{3}$ ), thereby confirming the prevalence of outer-sphere complexes. Therefore, the evident difference of sorption mechanisms in this former study may be due to differences in experimental conditions. While we have been working at comparable ionic strength, the $\mathrm{pH}$ was lower in Peak's study (4.5) as compared to our study (6.5). Furthermore, the former study employed a natural montmorillonite, while we employed a synthetic sample. (Whether or not these differences, for instance as regards the presence of impurities in the case of the natural montmorillonite, may be responsible for the observed differences, seems to be purely speculative).

The macroscopic adsorption of Se(IV) was predicted using the data from Boult et al. (1998) in $10 \mathrm{mM} \mathrm{NaCl}$ (Fig. 3). The data indicates that for a relatively high concentration of $\mathrm{Se}\left(10^{-4} \mathrm{~mol} / \mathrm{L}\right.$, similar to $5 \times 10^{-4} \mathrm{~mol} / \mathrm{L}$ used in our experiments $)$, the relative sorption is small (20\%), reaching a sorption plateau below pH 5 (Fig. 3). The maximum sorption capacity of $1 \mu \mathrm{mol} / \mathrm{g}$ is in agreement with previously published values $(1.5 \mu \mathrm{mol} / \mathrm{g}$ at $\mathrm{pH} 6-7$, Tan et al., 1994). The observed sorption edge is typical for weakly sorbing anions. the starting point of the absorption edge corresponds to the $\mathrm{pH}$ value, where the net charge of the functional groups at montmorillonite edge sites is expected to become positive based on the smectite MUSIC model (Tournassat 
et al., 2004c). The model predictions are therefore in agreement with the EXAFS data, supporting an outer-sphere complexation with positively charged edge sites.

The model of Tournassat et al. (2004c) was used to predict the Se sorption data. The simplest approach consists in defining Se sorption reactions with the same specific association constant for the two sites in the form of:

$$
\begin{array}{ll}
\mathrm{Si}-\mathrm{OH}^{+1 / 2}-\mathrm{Al}+\mathrm{HSeO}_{3}{ }^{-} \Leftrightarrow \mathrm{Si}-\mathrm{OH}^{+1 / 2}-\mathrm{Al}^{\cdots} \mathrm{HSeO}_{3}{ }^{-} & \log \mathrm{K}_{3}=16.5 \\
\mathrm{Al}-\mathrm{OH}_{2}{ }^{+1}-\mathrm{Al}+\mathrm{HSeO}_{3}{ }^{-} \Leftrightarrow \mathrm{Al}-\mathrm{OH}_{2}{ }^{+1}-\mathrm{Al}^{\cdots} \mathrm{HSeO}_{3}{ }^{-} & \log \mathrm{K}_{4}=16.5
\end{array}
$$

The associated $\log \mathrm{K}$ value was fitted in order to reproduce the start of the edge at pH 7-8. However, this simplistic model predicted a much higher sorption in agreement with the high surface density for these sites $(\sim 30 \mu \mathrm{mol} g-1$ for both sites, Tournassat et al., 2004c). In fact, only $1.5 \%$ of the available sites were necessary to obtain the fit shown in Fig. 3. This can be seen as the consequence of the negative structural charge of the clay that screens the positive charge of the edges (e.g. Avena, 2002; Chang and Sposito, 1996).

In contrast to selenite, $\mathrm{Fe}^{2+}$ is strongly sorbed by montmorillonite (Fig. 4, after Géhin et al., 2007). An adsorption edge is observed, which starts above pH 7. Below the sorption edge, much less $\mathrm{Fe}^{2+}$ is sorbed, following a $\mathrm{pH}$-independent pre-edge plateau (Fig. 4). According to the ${ }^{57}$ Fe Mössbauer results, this sorption plateau at low $\mathrm{pH}$ cannot be entirely attributed to cation exchange as for other metallic cations such as $\mathrm{Zn}$ or $\mathrm{Ni}$ (e.g. Baeyens and Bradbury, 1997). Instead, specific sorption and oxidation phenomena occur at $\mathrm{pH}$ values as low as pH 3 (Géhin et al., 2007). Based on the Mössbauer results, the sorption data could be successfully fitted using the 
model given in Table 1 (Fig. 4, insert). The sorbed Se and Fe concentrations observed during the kinetic experiment are presented in Figure 5. They are in good agreement with the sorption model. This is shown in Fig. 6, which shows the amount of sorbed $\mathrm{Fe}(\mathrm{II})$ in absence of Se using the experimental conditions of the present experiments modeled after Géhin et al. (2007). Fig. 7 shows the amount of Se(IV) in absence of iron as derived from the smectite MUSIC model (Table 1), together with the predicted amount of sorbed $\mathrm{Fe}(\mathrm{III})$ in absence of $\mathrm{Se}$ (see Mössbauer results below).

\subsection{Mössbauer results of the clay-Fe(II)-Se(IV) system}

Fig. 8 shows the paramagnetic Mössbauer spectra of select samples recorded at $77 \mathrm{~K}$ and their deconvolution into different $\mathrm{Fe}(\mathrm{II})$ and $\mathrm{Fe}(\mathrm{III})$ species. The corresponding hyperfine parameters are given in Table 2. Montmorillonite reacted with $\mathrm{Fe}^{2+}$ only, i.e. without selenite, shows two doublets $\mathrm{D}_{1}$ and $\mathrm{D}_{2}$ assigned to $\mathrm{Fe}(\mathrm{II})$ species (Fig. 8a, spectrum taken from Géhin et al. 2007). This species have been identified as $\mathrm{FeCl}^{+}$and $\mathrm{Fe}^{2+}$ bound to cation exchange sites (Charlet and Tournassat, 2005; Géhin et al., 2007). In addition, there is a third doublet $\mathrm{D}_{3}$ corresponding to $23 \%$ of $\mathrm{Fe}(\mathrm{III})$. Given the strictly anoxic conditions and the absence of any redox active metals in aqueous solution, in the montmorillonite solid and at the respective interface, the occurrence of this Fe(III) species is surprising. In a companion paper, Géhin et al. (2007) investigated this Fe redox phenomenon at the watermontmorillonite interface in detail and suggested that the oxidative agent responsible for this reversible oxidation is water.

Mössbauer spectra of the Fe(II)-clay samples reacted with selenite for $1 \mathrm{~h}$ and 5 days are shown in Fig. $8 \mathrm{~b}$ and $8 \mathrm{c}$. The $\mathrm{D}_{1}, \mathrm{D}_{2}$ and $\mathrm{D}_{3}$ doublets have hyperfine parameters similar to those in the absence of Se, suggesting that they represent similar 
species. In both samples, the two exchangeable Fe(II) species prevail $\left(\mathrm{D}_{1}+\mathrm{D}_{2}: 79\right.$ $86 \%$ ). However a striking fact appears which a priori could contradict the role of selenium as an electron acceptor: $23 \%$ of the total sorbed iron is oxidized in the absence of selenium, whereas only $4 \%$ of the sorbed iron is oxidized in the presence of selenium. This apparent contradiction is in fact due to differences in the experimental conditions used to prepare the $\mathrm{Fe}(\mathrm{II})$-clay and the $\mathrm{Se}(\mathrm{IV})-\mathrm{Fe}(\mathrm{II})$-clay samples. In the Se-rich samples (this study), we used a roughly ten times higher total $\mathrm{Fe}(\mathrm{II})$ concentration $\left(5 \mathrm{mmol} \mathrm{L}^{-1}\right)$ compared to the Se-free sample (study of Géhin et al., 2007) where $[\mathrm{Fe}(\mathrm{II})]_{\mathrm{t}}=630 \mu \mathrm{mol} \mathrm{\textrm {L } ^ { - 1 }}$. Note that in both studies the clay concentration $(20 \mathrm{~g} / \mathrm{L})$ and hence the site concentration $\left(90 \mu \mathrm{mol} \mathrm{L}^{-1}\right)$ was the same.

According to our sorption model under the present experimental conditions (Fig. 7), sorbed $\mathrm{Fe}(\mathrm{III})$ corresponds to 4 to $5.6 \%$ of the total sorbed Fe (pH 5.75 to 6.25 ). This value compares well with the 4 to $6 \%$ determined by Mössbauer spectrometry, suggesting that the addition of Se(IV) did not change the amount of this sorbed Fe(III) species. Furthermore, the Mössbauer spectra show little evolution within 1 hour and 5 days, hence the Fe speciation remains more or less constant, giving no indication for a slow Fe(II) oxidation after addition of selenite (Fig. 8).

After addition of selenite, a new Fe species is present, as indicated by the $D_{4}$ component in the Mössbauer spectra (Fig. 8 b, c). Its center shift values are indicative of $\mathrm{Fe}(\mathrm{II})$. The quadrupole splitting is even larger than that of the outer-sphere $\mathrm{FeCl}^{+}$ sorption complex (Charlet and Tournassat, 2005; Géhin et al., 2007). Since this component is linked to the addition of selenite, it may represent a $\mathrm{Fe}(\mathrm{II})$-selenite outer-sphere complex sorbed to the basal planes of montmorillonite. The relative abundance decreases from $15 \%$ to $10 \%$ between 1 hour and 5 days. In conclusion, 
none of the four observed Fe species suggests a coupled Fe-Se redox reaction after addition of selenite.

\subsection{XANES of the Clay-Fe(II)-Se(IV) system}

The evolution of selenite reduction over reaction time was monitored using Se Kedge XANES spectroscopy. Fig. 9 shows the spectra of the $\mathrm{Fe}^{2+}$-reacted montmorillonite samples after six time periods, plus a control without $\mathrm{Fe}^{2+}$ and three reference phases. The XANES spectra of the control and of the $\mathrm{Fe}^{2+}$ clay after short reaction periods are dominated by a white line at $12662 \mathrm{eV}$, which is characteristic for tetravalent $\mathrm{Se}$, hence represents as discussed above the adsorbed initial $\mathrm{SeO}_{3}{ }^{2-}$ outersphere sorption complex. With increasing time, the amplitude of the $\mathrm{Se}$ (IV) lines decreases, whereas a shoulder grows on its low-energy wing, which finally forms a separate peak at $12657 \mathrm{eV}$ after one month. This peak represents a reduced Se species.

In order to determine the number of spectral contributions, their identity and relative contribution, we analyzed the spectral data set with Iterative Transformation Factor Analysis (ITFA) (Rossberg et al., 2003). In contrast to using edge positions as proxies of oxidation state, this method has the advantage of making use of the combined information of oxidation state and coordination geometry contained in the XANES spectra. The seven clay spectra are superpositions of only two spectral components, as is demonstrated by the close fit between the experimental data (black) and their reconstruction with two Eigenvectors (red lines). Hence only the initial Se reactant and one reduced Se reaction product is present. A comparison with four references demonstrates that only grey $\operatorname{Se}(0)$ is a likely candidate for the reaction product. The precipitation of $\mathrm{FeSe}$ or $\mathrm{FeSe}_{2}$ as suggested by Bruggeman et al. 
(Bruggeman et al., 2005) can be excluded. Hence $\mathrm{SeO}_{3}{ }^{2-}$ is reduced to $\mathrm{Se}(0)$ in the presence of sorbed Fe.

\subsection{EXAFS of the clay-Fe(II)-Se(IV) system}

The evolution of Se reduction over reaction time was also monitored by Se Kedge EXAFS spectroscopy, revealing information on the local structure of the species (Fig. 10). Note that we were not able to collect an EXAFS spectrum for the sample reacted for one month. The $\mathrm{k}^{3}$-weighted EXAFS spectra reveal the formation of the reduced Se species by a splitting at $7 \AA^{-1}$ of the regular sinoidal oscillations representing the $\mathrm{O}$ coordination sphere. This feature represents an additional backscattering wave, corresponding to a peak at $2.2 \AA$ in the Fourier transform (distance not corrected for phase shift). The height of this peak increases with reaction time (Fig. 10).

Similar to the analysis of XANES spectra, we applied ITFA to the set of $\mathrm{k}^{3}$ weighted EXAFS spectra ( 3 to $11 \AA^{-1}$ ), hence investigating the expected change in local structure with time. As for the XANES spectra, the PCA of the EXAFS spectra showed only two significant components (Fig. 10). When $\operatorname{Se}(0)$ was included in the analysis however, the fit of the clay samples with longer reaction times was not adequate. This suggests that the structure of the reduced species is similar to but not identical with the $\mathrm{Se}(0)$ reference. To test this hypothesis, we performed ITT without the $\operatorname{Se}(0)$ reference, in order to extract the real spectrum of the second, $\operatorname{Se}(0)$-like component (Scheinost et al., 2005). By fixing only the concentration of the $\mathrm{Fe}^{2+}$-free control to unity, ITT failed to converge. Therefore, we iteratively fixed for the 4-day sample the relative concentration of the second component to values between 0.3 and 0.7. In agreement with the results from XANES (Fig. 9), a relative concentration of 
0.5 produced the most consistent result in terms of a minimum fit error and a minimum contribution of an $\mathrm{SeO}_{3}{ }^{2-}$ oxygen shell (Fig. 10).

\subsection{Solubility product analyses}

The combined $\mathrm{p} \varepsilon-\mathrm{pH}$ values measured during the course of the kinetic experiment are depicted in Figure 11. The values fall in the $\operatorname{Se}(0)$ stability domain, in agreement with XANES data. Linear regression of the $\mathrm{p} \varepsilon-\mathrm{pH}$ data yields a slope of -3.11 and an intercept of +22.52 . The slope is close to the theoretical -3.0 value, which has been derived for aqueous and sorbed $\mathrm{Fe}(\mathrm{II}) / \mathrm{FeOOH}(\mathrm{s})$ (see for example Silvester et al., 2005). Therefore the measured redox potential appears to be governed by the $\mathrm{Fe}(\mathrm{II}) / \mathrm{Fe}(\mathrm{III})$ couple:

$$
\mathrm{Fe}(\mathrm{OH})_{3}(\mathrm{~s})+3 \mathrm{H}^{+}+\mathrm{e}^{-}=\mathrm{Fe}^{2+}+3 \mathrm{H}_{2} \mathrm{O} \quad \mathrm{K}_{\mathrm{s}} \mathrm{K}_{\mathrm{Fe}}
$$

Where $\mathrm{Ks}$ is the solubility product of the $\mathrm{Fe}(\mathrm{OH})_{3}(\mathrm{~s})$ solid phase and $\mathrm{K}_{\mathrm{Fe}}$ is the $\mathrm{Fe}^{3+} / \mathrm{Fe}^{2+}$ one electron redox reaction constant $\left(\log \mathrm{K}_{\mathrm{Fe}}=13.05\right.$ at $\left.25^{\circ} \mathrm{C}\right)$. The line intercept and the activity of $\mathrm{Fe}^{2+}(\mathrm{aq})$ yield a $\mathrm{K}_{\mathrm{s}}$ value of $10^{6.7}$. This value is in between the ferrihydrite solubility products given in the $\operatorname{lnl}$ data base $\left(10^{5.65}\right)$ and that given in the Minteq v.4 database $\left(10^{3.2}\right)$ provided with PHREEQC2 (Parkhurst and Appelo, 1999). The high solubility of the $\mathrm{Fe}(\mathrm{OH})_{3}(\mathrm{~s})$ solid phase polymers formed by oxidation of the $\mathrm{Fe}^{2+}$ ions sorbed on the montmorillonite edges can be interpreted in terms of crystal size. Based on the dependence of the solubility product on crystal size and on surface tension (Enustun and Turkevich, 1960) and on the $10^{-2.1}$ crystallized goethite solubility product (Langmuir, 1969) one obtains $13.3 \AA$ Á wide Fe(III) polymers, assuming nanogoethite spherical particles with $20.6 \mathrm{~cm}^{3} / \mathrm{mol} \mathrm{molar}$ volume and $1.6 \mathrm{~J} / \mathrm{m}^{2}$ surface tension (Steefel and Van Cappellen, 1990). Such clusters could be hidden in the ferric part of the Mössbauer spectra as quadrupole 
doublets. Their size is close to $1.6 \mathrm{~nm}$, i.e. to the size observed by Small Angle X-ray scattering for $\mathrm{Fe}(\mathrm{III})$ clusters formed during the hydrolysis of $\mathrm{FeCl}_{3}$ solutions. These clusters are constituted of $24 \mathrm{Fe}(\mathrm{III})$ atoms and possess a local structure similar to that in $\alpha-\mathrm{FeOOH} / \beta-\mathrm{FeOOH}$ (Bottero et al., 1994).

Until now we assumed the reaction products to be pure $\mathrm{Fe}(\mathrm{III})$ solid phases. However, the Fe $\mathrm{III}^{\mathrm{II}}$ activity could also be controlled by mixed-valence amorphous Feoxides (MVA Fe-oxides) with solubility relations that resemble hydrated-magnetite (Schwab and Lindsay, 1983; Brennan and Lindsay, 1998). Under the assumption of metastable equilibrium, the stoichiometry of mineral species controlling Fe $\mathrm{Fe}^{\mathrm{II}}$ activity may be inferred from the slope of the data plotted as $[\mathrm{p} \varepsilon+\mathrm{pH}]$ versus $\left[\log \left(\mathrm{Fe}^{2+}\right)+2\right.$ pH]. While equilibrium with an $\mathrm{Fe}^{\mathrm{III}}$ mineral (e.g., ferrihydrite) yields a slope of -1 , magnetite $\left(\mathrm{Fe}^{\mathrm{II}} \mathrm{Fe}^{\mathrm{III}}{ }_{2} \mathrm{O}_{4}\right)$ gives a slope of -0.67 . Linear regression of our data yields a slope of -0.98 , also consistent with an Fe(III) precipitate. Furthermore, the activities of $\mathrm{Fe}^{2+}$ and $\mathrm{H}^{+}$, and therefore the slope of the best fit line in Fig. 11, are also affected by $\mathrm{Fe}^{2+}$ adsorption-desorption equilibria, as described in Table 1 . Because of this ambiguity regarding the impact of surface adsorbed $\mathrm{Fe}^{2+}$, standard thermodynamic predictions that redox dynamics in natural systems are in equilibrium with mixed $\mathrm{Fe}^{\mathrm{II}}-\mathrm{Fe}^{\mathrm{III}}$ solids must be interpreted cautiously.

\subsection{Evidence of formation of nano $\operatorname{Se}(0)$ clusters}

Fig. 10 shows the EXAFS spectra of the ITFA-derived two components in comparison with references. Component 1 represents the $\mathrm{Se}(\mathrm{IV})$ outer-sphere complex. As already suggested by the ITFA procedure, there is some deviation between component 2 and the $\mathrm{k}^{3}$-weighted EXAFS spectrum of $\operatorname{Se}(0)$. When comparing the two Fourier transforms, both spectra reveal backscattering shells at 
similar distances (2 and $3.2 \AA$, uncorrected for phase shift). However, the second shell of component 2 is significantly smaller than that of $\operatorname{Se}(0)$, suggesting a smaller coordination number or larger Debye-Waller factor.

To further investigate the structural relationship between component 2 and trigonal $\operatorname{Se}(0)$, we fitted both spectra in the same data range of $3 \leq \mathrm{k} \leq 11 \AA^{-1}$ (Table 4). In comparison to the trigonal $\mathrm{Se}(0)$ reference, atomic distances are slightly smaller in component 2. Furthermore, the coordination of the second shell is significantly smaller. Even though the coordination numbers are clearly biased by the short krange, one can infer a relatively small average cluster size for the newly formed precipitate. The larger Debye-Waller factors suggest a larger structural disorder (all samples were measured at $15 \mathrm{~K}$, where thermal vibrations should be negligible) for species 2. All features together suggest that the reduced species consist of nano-sized clusters with a higher structural disorder than $\operatorname{Se}(0)$.

Based on a comparison of their EXAFS spectra, ferroselite and the FeSe(IV) precipitates are not likely candidates for species 2 (Fig. 10), while tetragonal FeSe seems to provide a reasonable match. However, FeSe can be excluded for two reasons. First, the Fourier transform shows that its second Se shell is at a larger distance in comparison to component 2 and $\operatorname{Se}(0)$, which is further supported by the $\mathrm{ft}$ data (Table 3). Second, the XANES spectrum of FeSe clearly deviates from those of component 2 and $\operatorname{Se}(0)$ (Fig. 8). Hence the oxidation state and the coordination of component 2 are in disagreement with $\mathrm{FeSe}$ and in agreement with $\mathrm{Se}(0)$. In conclusion, the newly formed nano-particulate precipitate is $\operatorname{Se}(0)$. Considering a coordination $\mathrm{N}_{1}=2.5$ for the first shell and $\mathrm{N}_{2}=1.2$ for the second shell and assuming a spherical shape cluster centered on a Se atom, one obtains a cluster of ten atoms with a diameter of $0.8 \mathrm{~nm}$. 


\subsection{Homogeneous iron selenite precipitation}

In order to ensure that the observed $\mathrm{Se}(\mathrm{IV})$ reduction and $\mathrm{Se}(0)$ precipitation is a clay-water interfacial reaction and did not proceed via homogeneous precipitation from solution, we investigated the formation and structure of Fe selenite. The solid was precipitated by mixing equal volumes of $0.03 \mathrm{~mol} \mathrm{~L}^{-1} \mathrm{FeCl}_{2}$ and $\mathrm{Na}_{2} \mathrm{SeO}_{3}$ and aged for up to 5 days. The solution remained oversaturated with respect to the published solubility product of $\mathrm{FeSeO}_{3}\left(\mathrm{Ks}=10^{-9.99}\right.$, Seby et al., 2001). Other solids like $\mathrm{Na}_{2} \mathrm{Fe}\left(\mathrm{SeO}_{3}\right)_{2} \mathrm{Fe}_{2}\left(\mathrm{SeO}_{3}\right)_{2}$ or $\mathrm{Fe}_{2}\left(\mathrm{SeO}_{3}\right) 6 \mathrm{H}_{2} \mathrm{O}$ may precipitate as well, but to the best of our knowledge no solubility product has been published for these phases. Xray diffraction patterns after various aging periods exhibit very broad bands (data not shown), corresponding to poor crystallinity, which prevented the phase identification by this method.

XANES spectra recorded at the Se K-edge show no reduction of selenium after a 1 hour reaction time, and about 25\% reduction after 4 hours (shoulder at the low energy side in Fig. 9). The predominant oxidation state remains IV. The corresponding Mössbauer spectra (Fig. 8 and Table 2) show 50\% Fe(III), whereas Fe(III) never exceeded $4 \%$ of total iron in the reacted clay systems. The EXAFS spectrum of the 4-hour precipitate shows a selenite-like oxygen coordination sphere (1.9 $\mathrm{O}$ at $1.69 \AA$ ) and an additional backscattering shell fitted with $1.1 \mathrm{Fe}$ atoms at a distance of $3.35 \AA$ (Fig. 10). No first shell of a reduced species $(\operatorname{Se}(0)$ or lower) is visible. Hence Mössbauer spectrometry and EXAFS spectroscopy show a clear difference between the clay reaction product and the homogeneous FeSe(IV) 
precipitate. We can therefore conclude that homogeneous precipitation does not correspond to the reaction pathway observed for the Se(IV)-Fe(II)-clay system.

In order to reconcile the fact that half of the Fe atoms are present as $\mathrm{Fe}(\mathrm{III})$ in the poorly crystalline precipitate, while all Se atoms remain in a selenite-like local structure, we performed molecular dynamics calculations on bulk $\mathrm{FeSeO}_{3}(\mathrm{~s})$ and on its solid/water interface, followed by an interpretation of the resulting structures by the previously described Bond Valence method.. Since published Fe selenite structures contain only trivalent Fe (Giester, 1996; Giester and Wildner, 1991; Lafront et al., 1996), we used the structure of $\mathrm{Fe}(\mathrm{II}) \mathrm{SO}_{3}$ (Bugli and Carre, 1980) as starting point for our models after replacing S by Se.

The calculations on the bulk phase were based on the structure of one unit cell of $\mathrm{FeSeO}_{3}$. The forces between ions were calculated at every step and minimized until convergence in energy was reached. The resulting Fe-O bond lengths are shown in Table 4. Only one position for Fe was found with this method; the result was confirmed by Mulliken Population Analyses with DMol3 (Accelrys Software, Inc.). The bond valence sum for the bulk Fe(II) ions is $\mathrm{V}_{2+}=1.97$, very close to the nominal valence of 2 of $\mathrm{Fe}$ in this structure. Modeling the bulk data with the parameter for $\mathrm{Fe}(\mathrm{III})$ resulted in a bond valence sum $\mathrm{V}_{3^{+}}=2.11$, significantly lower than the value of 3 expected for $\mathrm{Fe}(\mathrm{III})$. Therefore, the analysis confirms that $\mathrm{Fe}(\mathrm{II})$ is the most favorable oxidation state in the bulk structure. The geometry optimization of the bulk $\mathrm{FeSeO}_{3}$ structure yields an average $\mathrm{Se}-\mathrm{O}$ bond length of $<\mathrm{d}_{\mathrm{Se}-\mathrm{O}}>=1.75 \AA$. This value is only slightly larger than the distance of $1.69 \AA$ determined by EXAFS for the precipitate, while the starting structure based on S had a much smaller S-O distance of $1.54 \AA$, supporting the reliability of our modeling approach. 
In the next step, we modeled the $\mathrm{FeSeO}_{3}$ /water interface. We used the (001) face of $\mathrm{FeSeO}_{3}$ in a box of $12 \times 12 \times 25 \AA$, where the upper half was filled with water molecules. Due to the periodic conditions of the box in the simulation, two $\mathrm{FeSeO}_{3} /$ water interfaces were simulated, one at the middle of the box and one at the bottom (Fig. 13). A first step of 1 ps accounts for the thermal equilibration at $300 \mathrm{~K}$ and a second step of $1.5 \mathrm{ps}$ accounts for the collection of the structural data. The temperature was set constant to $300 \mathrm{~K}$. The Fe atoms closer to the surface $(<3 \AA$ from the interface) have a mean Fe-O distance of $<\mathrm{d}_{\mathrm{Fe}-\mathrm{O} \text { surface }}>=2.02 \AA$ (Table 4). This mean value is significantly smaller that the corresponding value for bulk $\mathrm{FeSeO}_{3}$ $\left(<\mathrm{d}_{\mathrm{Fe}-\mathrm{O} \text { bulk }}>=2.15 \AA\right)$. Such a contraction could suggest an oxidation of $\mathrm{Fe}(\mathrm{II})$ to $\mathrm{Fe}(\mathrm{III})$.

The Fe-O bond lengths at the surface of $\mathrm{FeSeO}_{3}$ in contact with water were again analyzed with the bond-valence approach. The bond valence for $\mathrm{Fe}$ is $\mathrm{V}_{3^{+}}=3.05$, slightly oversaturated but very close to the nominal valence of $3+$. In contrast, the bond-valence sum assuming a valence of $2+$ is over saturated $\left(\mathrm{V}_{2+}=2.85\right)$. Consequently, our modeling approach predicts an oxidation of $\mathrm{Fe}$ at the $\mathrm{FeSeO}_{3}$ /water interface.

The Mössbauer data shows a contribution of $50 \%$ of Fe(II) and $50 \%$ of $\mathrm{Fe}(\mathrm{III})$. Assuming that the $\mathrm{Fe}(\mathrm{III})$ signal is from the iron atoms at the surface, and the Fe(II) is from iron atoms within the bulk structure, one can estimate an average particle size of about $2 \mathrm{~nm}$ for the $\mathrm{FeSeO}_{3}$ precipitate. This small particle size is further confirmed by the EXAFS-derived Se-Fe coordination number of 1.1 in comparison to the expected coordination number of 4 in the bulk structure. In conclusion, the EXAFS and Mössbauer data of the selenite precipitate is consistent with the formation of a nanoparticulate precipitate, where surface Fe atoms are oxidized, while the Se atoms 
remain in tetrahedral $\mathrm{O}$ coordination typical for selenite and hence do not show a clear trend towards a reduced oxidation state.

\subsection{Quantitative kinetics and mechanism of Se(IV) reduction}

Prior to the addition of Se(IV), the Fe(II)-clay suspensions were equilibrated at $\mathrm{pH} 6$, with most Fe sorbed as divalent outer-sphere species, while 4 to $6 \%$ of Fe was stabilized as trivalent inner-sphere species by specific sorption (Figs. 4 and 7). At time zero, $0.05 \mathrm{mmol} / \mathrm{L}$ of $\mathrm{Se}(\mathrm{IV})$ was added. The $\mathrm{pH}$ increased to values above 7 and then decreased again during the course of the experiment (Fig. 5, bottom). In spite of these pH shifts, the concentration of adsorbed selenium remained remarkably constant (Fig. 5, center). Our surface complexation computations predicted - based on the Boult et al. data (1998) - a selenium surface concentration of $0.8 \mathrm{mmol} / \mathrm{kg}$, a value that compares well with the measured concentration of $1.25 \mathrm{mmol} / \mathrm{kg}$ (Fig. 7). The measured amount of sorbed Fe (13-14\%) also compares well with the predicted amount (17\%) (Fig. 6).

The normalized speciation at each time step, as derived by ITFA from the XANES spectra (see above) is shown in the top part of Fig. 5. Table 5 gives the raw result of ITFA, demonstrating the reliability of the reconstruction with the sum of both species never exceeding $\pm 10 \%$. About $40 \%$ of Se(IV) is reduced within 6 hours and about $75 \%$ is reduced within one month. According to these relatively slow reaction kinetics, the reduction of $\mathrm{Se}(\mathrm{IV})$ to $\mathrm{Se}(0)$ is controlled by a time-limiting step, i.e. by the initial reducing capacity of the Fe-sorbed clay. Although a new hypothetical species appears in the Mössbauer spectra, this species, tentatively 
attributed to a $\mathrm{Se}(\mathrm{IV})-\mathrm{Fe}(\mathrm{II})$ clay ternary complex, may not represent the activated complex for the Se reduction step, as its concentration remains comparatively high.

After 5 days only half of the initial $\mathrm{Se}(\mathrm{IV})$ is reduced to $\mathrm{Se}^{\circ}$. This corresponds to an amount of $2.5 \mathrm{mmol} / \mathrm{kg}$ (or $50 \mu \mathrm{mol} / \mathrm{L}$ ) Fe oxidized to Fe(III). This value agrees well with the one predicted by the surface complexation model in the absence of Se and with the one measured by Mössbauer spectroscopy in the presence of Se $(\sim 2$ $\mathrm{mmol} / \mathrm{kg}$, Fig. 7). This means that once the sorbed Fe(II) is oxidized, Fe(III) occupies all high affinity sites and the Fe oxidation reaction is stopped without regeneration of the redox reactive sites. However, the electrons produced by the reaction and presumably stored as sorbed $\mathrm{H}_{2}$ species are available for the reaction with an oxidized ion such as $\mathrm{Se}(\mathrm{IV})$. The phenomenon that the reduction of $\mathrm{Se}(\mathrm{IV})$ is slow, although the oxidation of $\mathrm{Fe}(\mathrm{II})$ has already been completed, might suggest that the $\mathrm{Se}(\mathrm{IV})$ reduction is limited by the diffusion of Se(IV) to the newly formed reducing sites, or it might be limited by the diffusion of surface $\mathrm{H}_{2}$ to Se-sorbing sites. The overall reduction mechanism could then be written as:

$$
\begin{aligned}
& 4 \mathrm{~S}^{3+}\left(\mathrm{O}^{2-}\right)_{3} \mathrm{Fe}^{3+}\left(\mathrm{OH}^{-}\right)_{2} \cdots\left(\mathrm{H}_{2}\right)_{0.5}+\mathrm{HSeO}_{3}^{-} \\
& \Leftrightarrow 3 \mathrm{~S} \equiv{ }^{3+}\left(\mathrm{O}^{2-}\right)_{3} \mathrm{Fe}^{3+}\left(\mathrm{OH}^{-}\right)_{2}+\mathrm{S} \equiv^{3+}\left(\mathrm{O}^{2-}\right)_{3} \mathrm{Fe}^{3+}\left(\mathrm{OH}^{-}\right)_{3}+\mathrm{Se}^{0}+2 \mathrm{H}_{2} \mathrm{O}
\end{aligned}
$$

The amount of protons released in solution (Figure 5) is roughly two orders of magnitude smaller than the amount of selenium reduced. Due to the uncertainty on the proton mass balance of the overall reaction (which includes Se reduction, proton sorption on edges and particle dissolution), the stoichiometry of the above reaction must be considered cautiously.

\subsection{Environmental relevance}


In suboxic natural environments (hydromorphic soils, anaerobic groundwaters and sediments) and engineered systems (zero-valent iron permeable reactive barriers, and radioactive waste repository sites), aqueous $\mathrm{Fe}^{2+}$ is ubiquitous. In carbonate-rich, sulfide-poor surficial waters, the $\mathrm{Fe}^{2+}$ concentration is controlled by siderite $\left(\mathrm{FeCO}_{3(\mathrm{~s})}\right)$, green rust and Fe-rich calcite and varies between $10^{-4}$ and $10^{-2.5} \mathrm{~mol} \mathrm{~L}^{-1}$ depending on $\mathrm{pH}$ and $\mathrm{P}_{\mathrm{CO} 2}$ (Criaud and Fouillac, 1986a; Criaud and Fouillac, 1986b; Emerson, 1976; Postma, 1982). In more anoxic conditions, for example. in organicrich sulfide-rich environments, $\mathrm{Fe}^{2+}$ concentration is controlled by $\mathrm{FeS}_{\mathrm{x}}$ (where $1<\mathrm{x}<2$; mackinawite for $\mathrm{x}=1$ and pyrite for $\mathrm{x}=2$ ) and varies between $10^{-5}$ and $10^{-3}$ mol L ${ }^{-1}$ range (Balzer, 1982; Berner, 1971; Bott, 2002; Davison et al., 1999; Emerson et al., 1980; Wolthers et al., 2005; Gaucher et al., 2006). In low- $\mathrm{P}_{\mathrm{CO} 2}$, low- $\mathrm{P}_{\mathrm{H} 2 \mathrm{~S}}$ environments, $\mathrm{Fe}(\mathrm{II})$ solubility is controlled by the precipitation of $\mathrm{Fe}(\mathrm{OH})_{2(\mathrm{~s})}, \mathrm{Fe}_{3} \mathrm{O}_{4}$ (magnetite), green rust, or $\mathrm{Fe}_{3} \mathrm{PO}_{4(\mathrm{~s})}$. In the presence of steel, for example in near-field engineered barriers, Fe(II) concentrations typically lie between $10^{-6}$ and $3 \cdot 10^{-4} \mathrm{M}$ (Naftz et al., 2000). The dissolved $\mathrm{Fe}^{2+}$ concentration used in the present work $\left(510^{-4}\right.$ mol L ${ }^{-1}$ ) is hence representative of such environments.

Selenium is an essential trace element, which becomes toxic when present at high concentration. The maximum Se sorption capacity in China and California soils is 13$600 \mu \mathrm{g}$ Se per kg soil (Tan et al., 1994, White and Dubrovsky, 1994). Within the experimental conditions used in the present work (the maximum montmorillonite Se sorption capacity is $79 \mu \mathrm{g}$ Se per g of clay; Figure 3), the results obtained demonstrate that solubility in anoxic iron rich waters would be controlled by abiotically precipitated $\operatorname{Se}(0)$. The low solubility of $\operatorname{Se}(0), 3 \times 10^{-9} \mathrm{~mol} / \mathrm{L}$ (Bruggeman et al., 2005), would substantially reduce selenium mobility and toxicity. Over the past few 
decades, researchers have focused mainly on naturally occurring selenium, which is responsible for severe dietary toxicity-related diseases (Kesterson Reservoir, CA). It was noticed that anoxic deep waters in seleniferous areas of California, North West India and China had in fact very low concentrations of selenium (Dhillon and Dhillon, 2003; White and Dubrovsky, 1994, White et al., 1991). These low water concentrations were attributed to microbiological activity, as it is well known that cells reduce selenium to $\mathrm{Se}(0)$ as a detoxification pathway. The present work demonstrates however that, in the presence of the common phyllosilicate, montmorillonite and $\mathrm{Fe}^{2+}(\mathrm{aq})$, the reduction might be a totally abiotic process.

Recently, selenium has received renewed attention (e.g. Bruggeman et al., 2005) due to its presence as a fission product in high-level nuclear waste, where it exists as non-stable isotopes, e.g. ${ }^{79} \mathrm{Se} \quad(1.1$ million years half-life; http://www.nucleide.org/DDEP_WG/Nuclides/Se-79_com.pdf). In fact, recent nuclear waste disposal safety evaluations have demonstrated that anionic ${ }^{79} \mathrm{Se},{ }^{129} \mathrm{I},{ }^{36} \mathrm{Cl}$ and ${ }^{99} \mathrm{Tc}$ radionuclides might contribute most to the ultimate dose released during the next million years, as these anions were assumed to freely diffuse through clay confinement barriers (Toulhouat, 2002; ANDRA 2005; SKB 2006). The assessment to what extent ${ }^{79} \mathrm{Se}$ is a critical radionuclide at high-level radioactive waste disposal sites depends on its actual speciation and mobility under storage conditions. Until now, little data concerning the behavior of Se in geochemically reducing conditions has been published, mainly due to a lack of appropriate investigation techniques. By a combination of several spectroscopic techniques and extreme care to maintain anoxic conditions during sample preparation, storage, transport and measurements, we were able to tackle this problem. Our results suggest that the contribution of ${ }^{79} \mathrm{Se}$ to the risk 
of radioactive disposal sites could be smaller than previously assumed. This, however, has to be confirmed by experiments based on engineered barriers. 


\section{CONCLUSIONS}

Selenite adsorption on clay edges in the presence of aqueous $\mathrm{Fe}^{2+}$ results in the formation of $\mathrm{Se}^{\circ}$ nanoparticles. This is a kinetically controlled process, as demonstrated by the slow transition of the XANES selenite signal to a $\mathrm{Se}^{\circ}$ signal. A requirement for the observed heterogeneous reaction is that both iron and selenium are co-adsorbed at edge sites of clay; thus, the reaction is limited by the density of edge surface sites and the amount of sorbed iron. When all the iron present on the edges is consumed, the reaction stops. This surface-induced reductive precipitation mechanism profoundly influences the retention of selenium. Selenite sorption is minimal at high $\mathrm{pH}$ and decreases to zero when the positive charge of the edge sorption sites also decreases to zero. Although this site specific sorption has often been assumed to be negligible if compared with the large amount of cations exchangeably sorbed to the $\mathrm{pH}$-independent sites of montmorillonite and other similar clay minerals, the observed Se reduction demonstrates that such a quantitatively small process may control to a large extent the sequestration of Se in natural or engineered suboxic environments.

Homogeneous precipitation of $\mathrm{Fe}(\mathrm{II})$ and $\mathrm{Se}(\mathrm{IV})$ leads to 2-nm particles with part of the Fe being oxidized at the water interface, while selenium is only slightly reduced. Therefore, substantial Se reduction may occur only at a $\mathrm{pH}$ range, where both $\mathrm{Fe}$ and $\mathrm{Se}$ ions sorb to the mineral edges, i.e. below $\mathrm{pH}$ 7. Under these conditions, Se precipitates as stable, insoluble metallic clusters on the edge surface of smectite minerals, suggesting that reductive precipitation may be an effective and

relatively irreversible process that can abiotically regulate Se concentrations in reducing environments. Other forms of $\mathrm{Fe}(\mathrm{II})$ such as siderite, green rust or 
mackinawite may lead to the reductive precipitation of $\operatorname{Se}(0)$ as well. Furthermore, the influence of other geochemical parameters, such as $\mathrm{P}_{\mathrm{CO} 2}, \mathrm{pE}$ or $\mathrm{P}_{\mathrm{H} 2 \mathrm{~S}}$, should be investigated in the future in order to determine the long-term stability of Se in various reductive environments.

\section{Acknowledgments}

We would like to acknowledge partial financial support for this research from FUNMIG (European Union $6^{\text {th }}$ PCRD) and ANDRA (French National Radioactive Waste Management Agency). The achavalite sample ( $\left.{ }^{\circ} 42755\right)$ was kindly provided by Amédée Djemai, Mineralogy Museum, ENSM, Paris, and the XAS spectrum of ferroselite by Dan Strawn, University of Idaho, Moscow, Idaho. XRD spectra were performed by Nicolas Geoffroy. X-ray absorption spectroscopy was performed at the European Synchrotron Radiation Facility (Grenoble, France) on the Rossendorf Beamline, a facility operated by the Rossendorf Research Center (Germany). We acknowledge the help of Harald Funke, Andre Rossberg and Christoph Hennig during XAS data collection. 


\section{REFERENCES}

Anderson, S. J. and Sposito, G., 1991. Cesium-adsorption method for measuring accessible structural surface charge. Soil Science Society of America Journal $55,1569-1576$.

ANDRA, 2005. Dossier 2005 Argile. Référentiel du comportement des radionucléides et des toxiques chimiques d'un stockage dans le Callovo-Oxfordien jusqu'à l'homme.

Ankudinov, A. L. and Rehr, J. J., 1997. Relativistic spin-dependent X-ray absorption theory. Physical Review B 56.

Avena, M. J., 2002. Acid-base behavior of clay surfaces in aqueous media. Encyclopedia of surface and colloid science, 37-63.

Baeyens, B. and Bradbury, M. H., 1997. A mechanistic description of Ni and Zn sorption on Na-montmorillonite. Part I: Titration and sorption measurements. Journal of Contaminant Hydrology 27, 199-222.

Balistrieri, L. S. and Chao, T. T., 1990. Adsorption of selenium by amorphous iron oxyhydroxide and manganese dioxide. Geochimica et Cosmochimica Acta 54, 739-751.

Balzer, W., 1982. On the distribution of iron and manganese at the sediment / water interface: thermodynamic versus kinetic control. Geochimica et Cosmochimica Acta 46, 1153-1161.

Bar-Yosef, B. and Meek, D., 1987. Se sorption by kaolintite and montmorillonite. Soil Science 144, 11-19.

Barrow, N. J. and Whelan, B. R., 1989. Testing a mechanistic model .7. The effects of $\mathrm{pH}$ and of electrolyte on the reaction of selenite and selenate with a soil. Journal of Soil Science 40, 17-28.

Behrends, T. and Van Cappellen, P., 2005. Competition between enzymatic and abiotic reduction of uranium(VI) under iron reducing conditions. Chemical Geology 220, 315-327.

Belzile, N., Chen, Y. W., and Xu, R. R., 2000. Early diagenetic behaviour of selenium in freshwater sediments. Applied Geochemistry 15, 1439-1454.

Berkins, 2001. EOS Transactions 85, 57-58.

Berner, R. A., 1971. Principles of Chemical Sedimentology, McGraw-Hill.

Bidoglio, G., Gibson, P. N., Ogorman, M., and Roberts, K. J., 1993. X-ray-absorption spectroscopy investigation of surface redox transformations of thallium and chromium on colloidal mineral oxides. Geochimica et Cosmochimica Acta 57, 2389-2394.

Bond, D. L. and Fendorf, S., 2003. Kinetics and structural constraints of chromate reduction by green rusts. Environmental Science \& Technology 37, 27502757.

Bonhoure, I., Baur, I., Wieland, E., Johnson, C. A., and Scheidegger, A. M., 2006. Uptake of Se(IV/VI) oxyanions by hardened cement paste and cement 
minerals: An X-ray absorption spectroscopy study. Cement and Concrete Research 36, 91-98.

Bott, M., 2002. Iron sulfides in Baldeggersee during the last 8000 years: formation processes, chemical speciation and mineralogical constrains from EXAFS spectroscopy, ETH Zürich.

Bottero, J.Y., Manceau, A., Villieras, F., Tchoubar, D., 1994 Structure and mechanisms of formation of $\mathrm{FeOOH}(\mathrm{Cl})$ polymers. Langmuir 10:316-319..

Boult, K. A., Cowper, M. M., Heath, T. G., Sato, H., Shibutani, T., and Yui, M., 1998. Towards an understanding of the sorption of U(VI) and Se(VI) on sodium bentonite. Journal of Contaminant Hydrology 35, 141-150.

Bourg, I. C., Sposito, G., Bourg, A. C. M. 2007. Modeling the acid-base surface chemistry of montmorillonite. Journal of Colloid and Interface Science. In press.

Bradbury, M. H. and Baeyens, B., 1997. A mechanistic description of Ni and Zn sorption on Na-montmorillonite. Part II: modeling. Journal of Contaminant Hydrology 27, 223-248.

Brennan, E.W., Lindsay, W.L., 1998. Reduction and oxidation effect on the solubility and transformation of iron oxides. Soil Sci. Soc. Am. J. 62, 930-937.

Brown, I. D. and Altermatt, D., 1985. Bond-valence parameters obtained from a sytematic analysis of the inorganic crystal structure database. Acta Crystallographica B 41, 244-247.

Bruggeman, C., Maes, A., Vancluysen, J., and Vandemussele, P., 2005. Selenite reduction in Boom clay: Effect of FeS2, clay minerals and dissolved organic matter. Environmental Pollution 137, 209-221.

Bruggeman, C., Maes, A., Vancluysen, J., and Vandemussele, P., 2006. Selenite reduction in Boom clay: effect of $\mathrm{FeS}_{2}$, clay minerals and dissolved organic matter. Environmental Pollution 137, 209-21.

Buerge, E. J. and Hug, S., 1999. Influence of mineral surfaces on chromium (VI) reduction by Fe(II). Environmental Science and Technology 33, 4285-4291.

Bugli, G. and Carre, D., 1980. Structure cristalline du sulfite de Fer(II) anhydre $\mathrm{FeSO}_{3}$. Acta Crystallographica B 36, 1297-1300.

Cadene, A. Durand-Vidal, S., Turq, P., Brendle, J., 2004 Study of individual Namontmorillonite particles size, morphology, and apparent charge. Journal of Colloid and Interface Science 285, 719-730

Chang, F. R. C. and Sposito, G., 1996. The electrical double layer of a disked-shaped clay mineral particle: effect of electrolyte properties and surface charge density. Journal of Colloid and Interface Science 178, 555-564.

Charlet, L., Chakraborty, S., Varma, S., Tournassat, C., Wolthers, M., Chatterjee, D., and Roman-Ross, G., 2005. Adsorption and heterogeneous reduction of arsenic at the phyllosilicate-water interface. In: O'Day, P. A., Vlassopoulos, D., Meng, X., and Benning, L. G. Eds.), Advances in arsenic research. Integration of experimental and observational studies and implications for mitigation. ACS Symposium Series $\mathrm{N}^{\circ} 915$. 
Charlet, L., Schindler, P. W., Spadini, L., Furrer, G., and Zysset, M., 1993. Cation adsorption on oxides and clays: The aluminum case. Aquatic Science 55, 1015-1621.

Charlet, L. and Tournassat, C., 2005. Fe(II)-Na(I)-Ca(II) cation exchange on montmorillonite in chloride medium; evidence for preferential clay adsorption of chloride - metal ion pairs in seawater. Aquatic Geochemistry 11, 115-137.

Criaud, A. and Fouillac, C., 1986a. Etude des eaux thermominérales carbogazeuses du Massif Central français. I. Potentiel d'oxydo-réduction et comportement du fer. Geochimica et Cosmochimica Acta 50, 525-533.

Criaud, A. and Fouillac, C., 1986b. Etude des eaux thermominérales carbogazeuses du Massif Central français. II. Comportement de quelques métaux en trace, de l'arsenic, de l'antimoine, et du germanium. Geochimica et Cosmochimica Acta 50, 1573-1582.

Cuello, G. J., Piarrísteguy, A. A., Fernández-Martínez, A., Fontana, M., and Pradel, A., 2007. Structure of chalcogenide glasses by neutron diffraction. Journal of Non-Crystalline Solids.353, 729-732

Davison, W., Phillips, N., and Tabner, B. J., 1999. Soluble iron sulfide species in natural waters: reappraisal of their stoichiometry and stability constants. Aquatic Sciences 61, 23-43.

Delley, B. 1990. An all-electron numerical method for solving the local density functional for polyatomic molecules. Journal of Chemical Physics, 92, 508517.

Deverel, S.J., Fujii, R., 1988. Processes affecting the distribution of selenium in shallow groundwater of agricultural areas, Western San Joaquin Valley, California. Water Res. Res. 24, 516-534

Dhillon, K. S. and Dhillon, S. K., 2003. Quality of underground water and its contribution towards selenium enrichment in the soil-plant system for the seleniferous region of Northwest India. Journal of Hydrology 272, 120-130.

Doyle, C. S., Kendelewicz, T., Bostick, B. C., and Brown, G. E., 2004. Soft x-ray spectroscopic studies of the reaction of fractured pyrite surfaces with $\mathrm{Cr}(\mathrm{VI})$ containing aqueous solutions. Geochimica et Cosmochimica Acta 68, 42874299.

Duc, M., Lefevre, G., Fedoroff, M., Jeanjean, J., Rouchaud, J. C., Monteil-Rivera, F., Dumonceau, J., and Milonjic, S., 2003. Sorption of selenium anionic species on apatites and iron oxides from aqueous solutions. Journal of Environmental Radioactivity 70, 61-72.

Emerson, S., 1976. Early diagenesis in anaerobic lake sediments: chemical equilibria in intersticial waters. Geochimica et Cosmochimica Acta 40, 925-934.

Emerson, S., Jahnke, R., Bender, M., Froelich, P., Klinkhammer, G., Bowser, C., and Setlock, G., 1980. Early diagenesis in sediments from the eastern equatorial pacific. I. pore water nutrient and carbonate results. Earth Planete Science Letters 49, 57-80.

Ernustun, B.V., Turkevich, J., 1960 Solubility of fine particles of strontium sulfate. $J$. Am. Chem. Soc. 82, 4502-4509 
Ferrage, E., Tournassat, C., Rinnert, E., Charlet, L., and Lanson, B., 2005.

Experimental evidence for calcium-chloride ion pairs in the interlayer of montmorillonite. A XRD profile modelling approach. Clay and Clay Minerals 4, 348-361.

Filella, M., Belzile, N., and Chen, Y.-W., 2002. Antimony in the environment: a review focused on natural waters. I. Occurrence. Earth-Science Reviews 57, 125-176.

Fletcher, P. and Sposito, G., 1989. The chemical modeling of clay/electrolyte interactions for montmorillonite. Clay Minerals 24, 375-391.

Fordyce, F. 2005 Selenium deficiency and toxicity in the environment. In: Essentials of Medical Geology. Selinus 0. (ed.) Elsevier P. 373-415

Fredrickson, J. K., Zachara, J. M., Kennedy, D. W., Kukkadapu, R. K., McKinley, J. P., Heald, S. M., Liu, C. X., and Plymale, A. E., 2004. Reduction of $\mathrm{TcO}_{4}{ }^{-}$by sediment-associated biogenic Fe(II). Geochimica Et Cosmochimica Acta 68, 3171-3187.

Garbisu, C., Ishii, T., Leighton, T., and Buchanan, B. B., 1996. Bacterial reduction of selenite to elemental selenium. Chemical Geology 132, 199-204.

Gaucher et al., 2006

Géhin, A., Grenèche, J.-M., Tournassat, C., Brendlé, J., Rancourt, D. G., and Charlet, L., 2007. Reversible surface-sorption-induced electron-transfer oxidation of $\mathrm{Fe}(\mathrm{II})$ at reactive sites on a synthetic clay mineral. Geochimica et Cosmichimica Acta 71:863-876

Giester, G., 1996. Crystal structure of $\mathrm{Fe}_{2} \mathrm{O}\left(\mathrm{Se} \mathrm{O}_{3}\right)_{2}$, a new oxoselenite compound with ferric iron in distorted tetrahedral coordination. Zeitschrift fuer Kristallographie 211, 603-606.

Giester, G. and Wildner, M., 1991. Synthesis and crystal structure of monoclinic $\mathrm{Fe}_{2}\left(\mathrm{SeO}_{4}\right)_{3}$. Monatshefte fuer Chemie und verwandte Teile anderer Wissenschaften 122, 617-623.

Goldberg, S. and Traina, S. J., 1987. Chemical modeling of anion competition on oxides using the constant capacitance model-mixed-ligand approach. Soil Science Society of America Journal 51, 929-932.

Gruebel, K. A., Davis, J. A., and Leckie, J. O., 1995. Kinetics of oxidation of selenite to selenate in the presence of oxygen, titania and light. Environmental Science and Technology 29, 586-594.

Hartikainen, 2005 Biogeochemistry of selenium an dits impact on food chain quality and human health. J. Trace Elements Med Biol 18, 309-318

Hattenhoward, J., 1977. Geochemistry of selenium - Formation of ferroselite and selenium behavior in vicinity of oxidizing sulfide and uranium deposits. Geochimica et Cosmochimica Acta 41, 1665-1678.

Hayes, K. F., Roe, A. L., Brown, G. E., Hodgson, K. O., Leckie, J. O., and Parks, G. A., 1987. In situ X-ray adsorption study of surface complexes: selenium oxyanions on $\alpha-\mathrm{FeOOH}$. Science 238, 783-786. 
Hiemstra, T., De Wit, J. C. M., and Van Riemsdijk, W. H., 1989a. Multisite proton adsorption modelling at the solid/solution interface of (hydr)oxides: a new approach. II. Application to various important (hydr)oxides. Journal of Colloid and Interface Science 133, 105-117.

Hiemstra, T., Van Riemsdijk, W. H., and Bolt, G. H., 1989b. Multisite proton adsorption modelling at the solid/solution interface of (hydr)oxides: a new approach. I. Model description and evaluation of intrinsic reaction constants. Journal of Colloid and Interface Science 133, 91-104.

Hiemstra, T., Venema, P., and Van Riemsdijk, W. H., 1996. Intrinsic proton affinity of reactive surface groups of metal (hydr)oxides: the bond valence principle. Journal of Colloid and Interface Science 184, 680-692.

Ilton, E. S. and Veblen, D. R., 1994. Chromium sorption by phlogopite and biotite in acidic solutions at 25-Degrees-C - Insights from X-ray photoelectronspectroscopy and electron-microscopy. Geochimica et Cosmochimica Acta 58, $2777-2788$

Johnson, C.C.,Ge X., Green, K.A., Liu X. , 2000 Selenium distribution in the local environment of selected villages of the Keshan Disease belt, Zhangjiakou District, Hebei Province, People's Republic of China. Appl. Geochem. 15, 385-401

Kamei, G., Oda, C., Mitsui, S., Shibata, M., and Shinozaki, T., 1999. Fe(II)-Na ion exchange at interlayers of smectite: adsorption-desorption experiments and a natural analogue. Engineering Geology 54, 15-20.

Kresse, G. and Hafner, J. B., 1993. Ab initio molecular dynamics for liquid metals. Physical Review B 47, 558-561.

Lafront, A. M., Bonvoisin, J., and Trombe, J. C., 1996. Synthesis, crystal structure, and magnetic measurement of two new diselenites: $\mathrm{M}_{2}\left(\mathrm{Se}_{2} \mathrm{O}_{5}\right)_{3}$ with $\mathrm{M}=$ $\mathrm{Fe}(\mathrm{III}), \mathrm{Cr}(\mathrm{III})$. Journal of Solid State Chemistry 122, 130-138.

Langmuir, D., 1969. The Gibbs free energies of substances in the system $\mathrm{Fe}-\mathrm{O}_{2}-\mathrm{H}_{2} \mathrm{O}-$ $\mathrm{CO}_{2}$ at 25 degrees C. In Geological Survey research 1969. Edited by Publications ofthe U. S. Geological Survey; B180-B184.

Legrand, L., El Figuigui, A., Mercier, F., and Chausse, A., 2004. Reduction of aqueous chromate by $\mathrm{Fe}(11) / \mathrm{Fe}(111)$ carbonate green rust: Kinetic and mechanistic studies. Environmental Science \& Technology 38, 4587-4595.

Leuz, A.-K. and Johnson, C. A., 2005. Oxidation of $\mathrm{Sb}(\mathrm{III})$ to $\mathrm{Sb}(\mathrm{V})$ by $\mathrm{O}_{2}$ and $\mathrm{H}_{2} \mathrm{O}_{2}$ in aqueous solutions. Geochimica et Cosmochimica Acta 69, 1165-1172.

Liger, E., Charlet, L., and Van Cappellen, P., 1999. Surface catalysis of uranium(VI) reduction by iron(II). Geochimica et Cosmochimica Acta 63, 2939-2955.

Loyaux-Lawniczak, S., Refait, P., Ehrhardt, J. J., Lecomte, P., and Genin, J. M. R., 2000. Trapping of $\mathrm{Cr}$ by formation of ferrihydrite during the reduction of chromate ions by $\mathrm{Fe}(\mathrm{II})-\mathrm{Fe}(\mathrm{III})$ hydroxysalt green rusts. Environmental Science \& Technology 34, 438-443.

Manceau, A. and Charlet, L., 1994. The mechanism of selenate adsorption on goethite and hydrous ferric oxide. Journal of Colloid and Interface Science 168, 87-93. 
Monteil-Rivera, F., Fedoroff, M., Jeanjean, J., Minel, L., Barthes, M. G., and Dumonceau, J., 2000. Sorption of selenite $\left(\mathrm{SeO}_{3}{ }^{2-}\right)$ on hydroyapatite: An exchange process. Journal of Colloid and Interface Science 221, 291-300.

Mullet, M., Boursiquot, S., and Ehrhardt, J. J., 2004. Removal of hexavalent chromium from solutions by mackinawite, tetragonal FeS. Colloids and Surfaces A - Physicochemical and Engineering Aspects 244, 77-85.

Myneni, S. C. B., Tokunaga, T. K., and Brown, G. E., 1997. Abiotic selenium redox transformations in the presence of Fe(II,III) oxides. Science 278, 1106-1109.

Naftz, D. L., Feltcorn, E. M., Fuller, C. C., Wilhelm, R. G., Davis, J. A., Morrison, S. J., Freethey, G. W., Piana, M. J., Rowland, R. C., and Blue, J. E., 2000. Field demonstration of permeable reactive barriers to remove dissolved uranium from groundwater, Fry Canyon, Utah. United State Environmental Protection Agency, Washington D.C.

Neal, R. H. and Sposito, G., 1989. Selenate adsorption on alluvial soils. Soil Science Society of America Journal 53, 70-74.

Neal, R. H., Sposito, G., Holtzclaw, K. M., and Traina, S. J., 1987a. Selenite adsorption on alluvial Soils .1. Soil composition and $\mathrm{pH}$ effects. Soil Science Society of America Journal 51, 1161-1165.

Neal, R. H., Sposito, G., Holtzclaw, K. M., and Traina, S. J., 1987b. Selenite adsorption on alluvial soils .2. Solution composition effects. Soil Science Society of America Journal 51, 1165-1169.

Oremland, R. S., Hollibaugh, J. T., Maest, A. S., Presser, T. S., Miller, L. G., and Culbertson, C. W., 1989. Selenate reduction to elemental selenium by anaerobic bacteria in sediments and culture - Biogeochemical significance of a novel, sulfate-independent respiration. Applied and Environmental Microbiology 55, 2333-2343.

Oremland, R. S. and Steinberg, N. A., 1990. Bacterial dissimilatory selenate reduction in sediments. Abstracts of Papers of the American Chemical Society 199, 5GEOC.

Patterson, R. R., Fendorf, S., and Fendorf, M., 1997. Reduction of hexavalent chromium by amorphous iron sulfide. Environmental Science \& Technology 31, 2039-2044.

Parkhurst, D.L., Appelo, C.A.J. 1999. User's guide to phreeqc - a computer program for speciation, batch-reaction, one-dimensional transport, and inverse geochemical calculations, USGS Report No. 99-4259.

Pauling, L., 1929. The principles determining the structure of complex ionic crystals. Journal of the American Chemical Society 52, 1010-1026.

Peak, D. and Sparks, D. L., 2002. Mechanisms of selenate adsorption on iron oxides and hydroxides. Environmental Science and Technology 36, 1460-1466.

Peak, D., Saha, U. K., Huang, P. M., 2006. Selenite adsorption mechanisms in pure and coated Montmorillonite: An EXAFS and XANES spectroscopic study. Soil Sci. Soc. Am. J., 70, 192-203.

Perdew, J. P.; Burke, K.; Ernzerhof, M. 1996. General Gradient Approximation made simple. Physical Review Letters, 77, 3865. 
Persson, P., Nilsson, N., Sjoberg, S., 1996. Structure and bonding of ortophosphate ions at the iron oxide-aqueous interface. J. Colloid and Interface Science, 177, 263-275.

Peterson, M. L., White, A. F., Brown, G. E., and Parks, G. A., 1997. Surface passivation of magnetite by reaction with aqueous $\mathrm{Cr}(\mathrm{VI})$ : XAFS and TEM results. Environmental Science \& Technology 31, 1573-1576.

Postma, D., 1982. Pyrite and siderite formation in brackish and freshwater swamp sediments. American Journal of Science 282, 1151-1183.

Reinholdt, M., Miehe-Brendle, J., Delmotte, L., Le Dred, R., and Tuilier, M. H., 2005. Synthesis and characterization of montmorillonite-type phyllosilicates in a fluoride medium. Clay Minerals 40, 177-190.

Reinholdt, M., Miéhé-Brendlé, J., Delmotte, L., Tuillier, M.-H., de Dred, R., Cortès, R., and Flank, A.-M., 2001. Fluorine route synthesis of montmorillonites containing $\mathrm{Mg}$ or $\mathrm{Zn}$ and characterization by XRD, thermal analysis, MAS NMR, and EXAFS spectroscopy. European Journal of Organic Chemistry.

Ressler, T., 1998. WinXAS: a program for X-ray absorption spectroscopy data analysis under MS-Windows. Journal of Synchrotron Radiation 5, 118-122.

Rossberg, A., Reich, T., and Bernhard, G., 2003. Complexation of uranium(VI) with protocatechuic acid - application of iterative transformation factor analysis to EXAFS spectroscopy. Analytical and Bioanalytical Chemistry 376, 631-638.

Scheinost, A. C., Rossberg, A., Marcus, M., Pfister, S., and Kretzschmar, R., 2005. Quantitative zinc speciation in soil with XAFS spectroscopy: Evaluation of iterative transformation factor analysis. Physica Scripta T115, 1038-1040.

Schwab, A.P., Lindsay, W.L., 1983. Effect of redox on the solubility and availability of iron. Soil Sci. Soc. Am. J. 47, 201-205.

Seby, F., Potin-Gautier, M., Giffaut, E., Borge, G., and Donard, O. F. X., 2001. A critical review of thermodynamic data for selenium species at $25^{\circ} \mathrm{C}$. Chemical Geology 171, 173-194.

Silvester, E., Charlet, L., Tournassat, C., Géhin, A., Grenèche, J. M., and Liger, E., 2005. Redox properties of Fe-II adsorbed onto Fe-III (oxyhydr)oxides. Geochimica et Cosmochimica Acta 69, 4801-4815.

SKB (2006), Data report for the safety assessment of SR-Can, SKB Technical Report TR-06-25, Stockholm, Sweden.

Sorensen, J. and Thorling, L., 1991. Stimulation by lepidocrocite $(\gamma-\mathrm{FeOOH})$ of Fe(II)-dependent nitrite reduction. Geochimica et Cosmochimica Acta 55, 1289-1294.

Stadler, M. and Schindler, P. W., 1993. Modeling of $\mathrm{H}^{+}$and $\mathrm{Cu}^{2+}$ adsorption on calcium-montmorillonite. Clays and Clay Minerals 41, 288-296.

Steefel, C.I. Van Cappellen, P. 1990 A new kinetic approach to modeling water-rock interaction: the role of nucleation, precursors and Ostwald ripening Geochimica et Cosmochimica Acta 1990, 54:2657-2677. 
Su, C. M. and Suarez, D. L., 2000. Selenate and selenite sorption on iron oxides: An infrared and electrophoretic study. Soil Science Society of America Journal 64, 101-111.

Tan, J. A., Wang, W. Y., Wang, D. C., and Hou, S. F., 1994. Adsorption, volatilization and speciation of selenium in different types of soils in China. In: Frankenberger, W. T. and Benson, S. Eds.), Selenium in the Environment Dekker Publication, New York.

Thompson A., Chadwick, O.A., Rancourt, D.G., Chorover, J. ,2006 Iron-oxide crystallinity increases during soil redox oscillations Geochimica et Cosmochimica Acta 70, 1710-1727

Tokunaga, T. K., Brown, G. E., Pickering, I. J., Sutton, S. R., and Bait, S., 1997. Selenium redox reactions and transport between ponded waters and sediments. Environmental Science \& Technology 31, 1419-1425.

Toulhouat, P., 2002. Confinement and migration of radionuclides in a nuclear waste deep repository. Comptes-rendu de Physique 3, 975-986.

Tournassat, C., Charlet, L., and Greneche, J. M., 2004a. Interactions of $\mathrm{Fe}^{2+}, \mathrm{Zn}^{2+}$, and $\mathrm{H}_{4} \mathrm{SiO}_{4}$ at clay/water interface: distinguishing competitive sorption, coadsorption and surface oxidation phenomena. Geochimica et Cosmochimica Acta 68, A162.

Tournassat, C., Ferrage, E., Poinsignon, C., and Charlet, L., 2004b. The titration of clay minerals. Part II. Structural based model and implications on clay reactivity. Journal of Colloid and Interface Science 273, 238-250.

Tournassat, C., Greneche, J.-M., Tisserand, D., and Charlet, L., 2004c. The titration of clay minerals. Part I. Discontinuous backtitration technique combined to CEC measurements. Journal of Colloid and Interface Science 273, 228-237.

Velinsky, D. J. and Cutter, G. A., 1990. Determination of elemental selenium and pyrite-selenium in sediments. Analytica Chimica Acta 235, 419-425.

Velinsky, D. J. and Cutter, G. A., 1991. Geochemistry of selenium in a coastal saltmarsh. Geochimica et Cosmochimica Acta 55, 179-191.

Viollier, E., Inglett, P. W., Hunter, K., Roychoudhury, A. N., and Van Cappellen, P., 2000. The ferrozine method revisited : $\mathrm{Fe}(\mathrm{II}) / \mathrm{Fe}(\mathrm{III})$ determination in natural waters. Applied Geochemistry 15, 785-790.

Wanner, H., Albinson, Y., Karnland, O., Wieland, E., Wersin, P., and Charlet, L., 1994. The acid/base chemistry of montmorillonite. Radiochimica Acta 66/67, 157-162.

Wen, H. J., Carignan, J., Qlu, Y. H., and Liu, S. R., 2006. Selenium speciation in kerogen from two chinese selenium deposits: Environmental implications. Environmental Science \& Technology 40, 1126-1132.

White, A. F. and Dubrovsky, N. M., 1994. Chemical oxidation-reduction controls on selenium mobility in groundwater systems. In: Frankenberger, W. T. and Benson, S. Eds.), In Selenium in the Environment. Dekker Publication, New York. 
White, A. F. and Peterson, M. L., 1996. Reduction of aqueous transition metal species on the surfaces of Fe(II)-containing oxides. Geochimica et Cosmochimica Acta 60, 3799-3814.

White, A.F., Benson, S.M., Yee, A.W., Wollenberg, H.A., Flexer, S. 1991 Goundwater contamination at the Keterson Reservoir, California 2. Geochemical parameters influencing selenium mobility Water Res. Res. 27 : 1085-1098

White, G. N. and Zelazny, L. W., 1988. Analysis and Implications of the Edge Structure of Dioctahedral Phyllosilicates. Clays and Clay Minerals 36, 141146.

Wilkin, R. T., Su, C. M., Ford, R. G., and Paul, C. J., 2005. Long-term geochemical behavior of a zerovalent iron permeable reactive barrier for the treatment of hexavalent chromium in groundwater. Geochimica et Cosmochimica Acta 69, A264-A264.

Williams, A. G. B. and Scherer, M. M., 2004. Spectroscopic evidence for Fe(II)$\mathrm{Fe}(\mathrm{III})$ electron transfer at the Fe oxide-water interface. Environmental Science and Technology 38, 4782-4790.

Wolthers, M., Charlet, L., Van der Linde, P. R., Rickard, D., and van der Weijden, C. H., 2005. The surface chemistry of disordered mackinawite. Geochimica et Cosmochimica Acta 69, 3469-3481.

Xiong, Y. L., 2003. Predicted equilibrium constants for solid and aqueous selenium species to 300 degrees C: applications to selenium-rich mineral deposits. Ore Geology Reviews 23, 259-276.

Zachara, J. M. and Smith, S. C., 1994. Edge complexation reactions of cadmium on specimen and soil-derived smectite. Soil Science Society of America Journal 58, 762-769.

Zachara, J. M., Smith, S. C., McKinley, J. P., and Resch, C. T., 1993. Cadmium sorption on specimen and soil smectites in sodium and calcium electrolytes. Soil Science Society of America Journal 57, 1491-1501.

Zhang, P. and Sparks, D. L., 1990. Kinetics of selenate and selenite adsorption/desorption at the goethite/water interface. Environmental Science \& Technology 24, 1848-1856.

Zhang, Y. Q. and Moore, J. N., 1997. Interaction of selenate with a wetland sediment. Applied Geochemistry 12, 685-691. 
Table 1. List of reactions and their equilibrium constants as used in the non electrostatic, smectite MUSIC model (Tournassat et al., 2004c) and in the Fe sorption model of Géhin et al. (submitted).

\begin{tabular}{|c|c|c|}
\hline Reactions & $\log \mathrm{K}$ & $\begin{array}{l}\text { Site conc. } \\
(\mathrm{mmol} / \mathrm{kg})\end{array}$ \\
\hline \multicolumn{3}{|l|}{ Cation Exchange } \\
\hline$X \mathrm{Na}+H^{+} \Leftrightarrow X H+N a^{+}$ & $0^{\ddagger}$ & \\
\hline $2 \mathrm{XNa}+\mathrm{Ca}^{2+} \Leftrightarrow \mathrm{X}_{2} \mathrm{Ca}+2 \mathrm{Na}^{+}$ & $0.5^{\ddagger}$ & \\
\hline $\mathrm{XNa}+\mathrm{CaCl}^{+} \Leftrightarrow \mathrm{XCaCl}+\mathrm{Na}^{+}$ & $2.5^{\ddagger}$ & $440^{\S}$ \\
\hline $2 \mathrm{XNa}+\mathrm{Fe}^{2+} \Leftrightarrow \mathrm{X}_{2} \mathrm{Fe}+2 \mathrm{Na}^{+}$ & $0.4^{\ddagger}$ & \\
\hline $\mathrm{XNa}+\mathrm{FeCl}^{+} \Leftrightarrow \mathrm{XFeCl}+\mathrm{Na}^{+}$ & $2.3^{\ddagger}$ & \\
\hline \multicolumn{3}{|l|}{ Edge protonation } \\
\hline$S i-O^{-1 / 2}-A l+H^{+} \Leftrightarrow S i-O H^{+1 / 2}-A l$ & -7.2 & 31 \\
\hline $\mathrm{Al}-\mathrm{OH}-\mathrm{Al}+\mathrm{H}^{+} \Leftrightarrow \mathrm{Al}-\mathrm{OH}_{2}^{+1}-\mathrm{Al}$ & -4.8 & 34 \\
\hline \multicolumn{3}{|l|}{ Selenium adsorption } \\
\hline $\mathrm{Si}-\mathrm{OH}^{+1 / 2}-\mathrm{Al}+\mathrm{HSeO}_{3}^{-} \Leftrightarrow \mathrm{Si}-\mathrm{OH}^{+1 / 2}-\mathrm{Al}^{\cdots} \mathrm{HSeO}_{3}^{-}$ & 16.5 & $0.5(-1.5 \% \times 31)$ \\
\hline $\mathrm{Al}-\mathrm{OH}_{2}^{+1}-\mathrm{Al}+\mathrm{HSeO}_{3}^{-} \Leftrightarrow \mathrm{Al}-\mathrm{OH}_{2}^{+1}-\mathrm{Al}^{\cdots} \mathrm{HSeO}_{3}^{-}$ & 16.5 & $0.5(-1.5 \% \times 34)$ \\
\hline
\end{tabular}

Fe sorption on clay edges ${ }^{¥}$

$$
\begin{aligned}
& \mathrm{Fe}^{2+}+\mathrm{s}^{1} \equiv^{3+}(\mathrm{OH})_{3} \\
& \Leftrightarrow s^{l} \equiv^{3+}(\mathrm{OH})\left(\mathrm{O}^{2-}\right)_{2} \mathrm{Fe}^{2+}+2 \mathrm{H}^{+}{ }_{a q} \\
& \mathrm{~s}^{\mathrm{l}} \equiv^{3+}(\mathrm{OH})\left(\mathrm{O}^{2-}\right)_{2} \mathrm{Fe}^{2+}+2 \mathrm{H}_{2} \mathrm{O} \\
& \Leftrightarrow s^{l} \equiv^{3+}\left(\mathrm{O}^{2-}\right)_{3} \mathrm{Fe}^{3+}\left(\mathrm{OH}^{-}\right)_{2} \cdots\left(\mathrm{H}_{2}\right)_{0.5}+2 \mathrm{H}^{+} \text {aq } \\
& \mathrm{Fe}^{2+}+\mathrm{s}^{2} \equiv^{3+}(\mathrm{OH})_{3} \\
& \Leftrightarrow \mathrm{s}^{2} \equiv^{3+}\left(\mathrm{OH}^{-}\right)\left(\mathrm{O}^{2-}\right)_{2} \mathrm{Fe}^{2+}+2 \mathrm{H}^{+}{ }_{a q} \\
& \mathrm{~s}^{2} \equiv^{3+}\left(\mathrm{OH}^{-}\right)\left(\mathrm{O}^{2-}\right)_{2} \mathrm{Fe}^{2+}+2 \mathrm{H}_{2} \mathrm{O} \\
& \Leftrightarrow s^{2} \equiv^{3+}\left(\mathrm{O}^{2-}\right)_{3} \mathrm{Fe}^{3+}(\mathrm{OH})_{2} \cdots\left(\mathrm{H}_{2}\right)_{0.5}+2 \mathrm{H}^{+} \mathrm{aq} \\
& 2 \exists \mathrm{wOH}+\mathrm{Fe}^{2+}+\mathrm{H}_{2} \mathrm{O} \\
& \Leftrightarrow \Rightarrow w_{2} \mathrm{O}_{2} \mathrm{FeOH}+3 \mathrm{H}^{+}
\end{aligned}
$$

AAfter Charles and Tournassat (2005), Gaines and Thomas thermodynamic convention.

${ }^{\S}$ From Cs-Li method (Anderson and Sposito, 1991).

${ }^{¥}$ Model from Géhin et al. (submitted). 
Table 2. Mössbauer hyperfine parameters of the spectra presented in Fig. $7 . \delta\left(\mathrm{mm} \mathrm{s}^{-1}\right)$ isomer shift with respect to metallic $\alpha-\mathrm{Fe}(0)$ at room temperature; $\Delta \mathrm{E}_{\mathrm{Q}}\left(\mathrm{mm} \mathrm{s}^{-1}\right)$ quadrupole splitting; RA (\%) relative abundance.

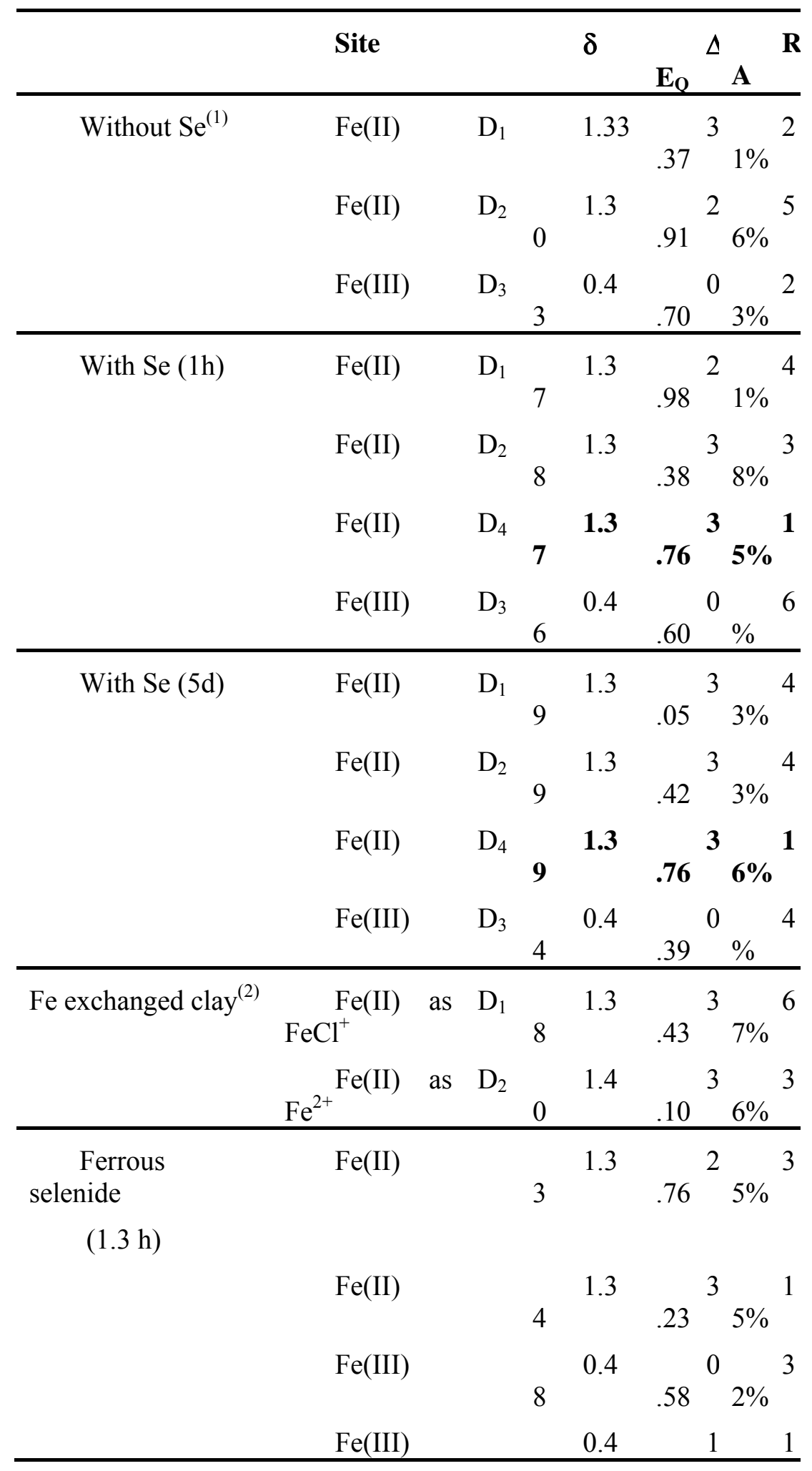




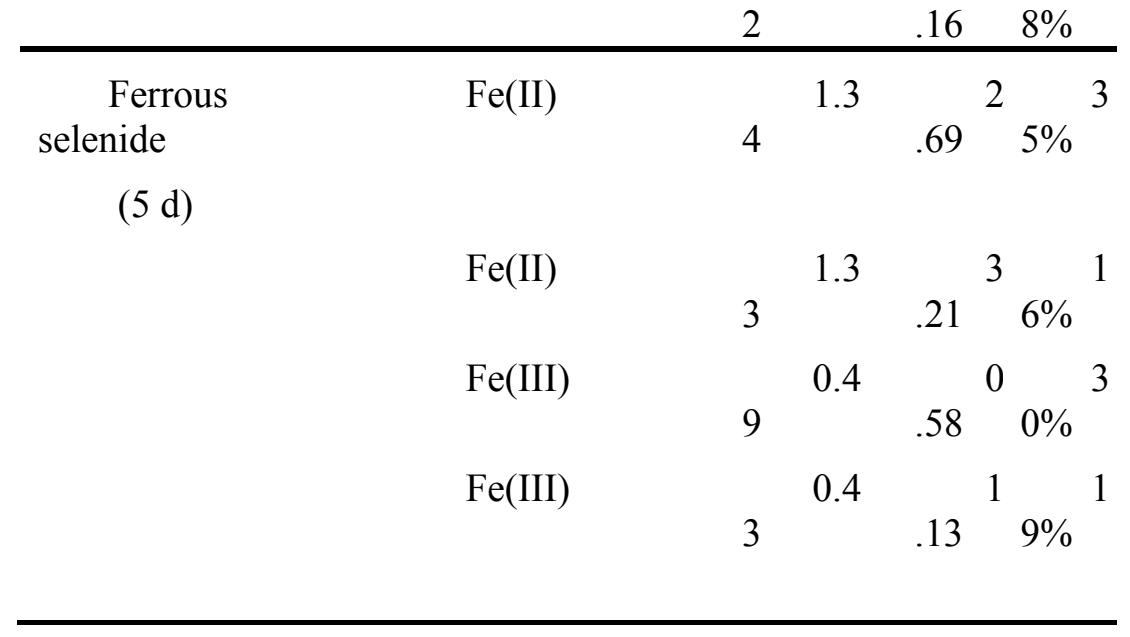

(1) Data and fit from (Géhin et al., submitted)

(2) Data and fit from (Charlet and Tournassat, 2005) 
Table 3. Se K-edge EXAFS multishell fit results of Se(IV) sorbed montmorillonite, ITFA-derived spectral component 2 , and of two references.

\begin{tabular}{cccccc}
\hline Sample & & & & $\Delta \mathrm{E}_{0}[\mathrm{eV}]^{*}$ & $\chi_{\text {res }{ }^{\dagger}}^{\dagger}$ \\
& $\mathrm{CN}^{\ddagger}$ & $\begin{array}{c}\mathrm{R} \\
{[\AA]^{\S}}\end{array}$ & $\sigma^{2}\left[\AA^{2}\right]^{* *}$ & & \\
\hline $\begin{array}{c}\text { Se(IV) sorbed } \\
\text { montmorillonite }\end{array}$ & $2.8 \mathrm{O}$ & 1.70 & 0.0016 & 9.3 & 4.7 \\
Component 2 & $2.5 \mathrm{Se}$ & 2.36 & 0.0057 & 8.9 & 7.7 \\
& $1.2 \mathrm{Se}$ & 3.26 & 0.0100 & & \\
& $1.3 \mathrm{Se}$ & 3.66 & 0.0071 & & \\
trigonal Se(0) & $2.0 \mathrm{Se}$ & 2.39 & 0.0028 & 8.4 & 4.2 \\
& $4.8 \mathrm{Se}$ & 3.39 & 0.0070 & & \\
& $1.0 \mathrm{Se}$ & 3.74 & 0.0026 & & \\
tetragonal FeSe & $3.8 \mathrm{Se}$ & 2.38 & 0.0017 & 4.3 & 5.2 \\
& $8.9 \mathrm{Se}$ & 3.70 & 0.0084 & & \\
& $2.1 \mathrm{Se}$ & 3.96 & 0.0010 & & \\
& $7.7 \mathrm{Fe}$ & 4.43 & 0.0025 & & \\
\hline
\end{tabular}

* Phase shift

${ }^{\dagger}$ Fit error

$\star$ Coordination number

$\S$ Atomic distance

${ }^{* *}$ Debye-Waller factor 
Table 4. Bond-valence model for Fe-O bonds in bulk $\mathrm{FeSeO}_{3}$ and on the water $/ \mathrm{FeSeO}$ interface.

\begin{tabular}{ccc|ccc}
\multicolumn{3}{c}{ BULK } & \multicolumn{3}{|c}{ WATER INTERFACE } \\
\hline & \multicolumn{3}{c|}{$\mathbf{s}_{\mathrm{ij}}$} & & \multicolumn{3}{c}{$\mathbf{s}_{\mathrm{ij}}$} \\
& $\mathbf{2 +}$ & $\mathbf{3 +}$ & & $\mathbf{2 +}$ & $\mathbf{3 +}^{+}$ \\
$\mathbf{d}_{\text {Fe-0 }}$ & $\mathbf{R}_{\mathbf{0}}=\mathbf{1 . 7 3 4}$ & $\mathbf{R}_{\mathbf{0}}=\mathbf{1 . 7 5 9}$ & $\mathbf{d}_{\text {Fe-0 }}$ & $\mathbf{R}_{\mathbf{0}}=\mathbf{1 . 7 3 4}$ & $\mathbf{R}_{\mathbf{0}}=\mathbf{1 . 7 5 9}$ \\
2.250 & 0.2479 & 0.2652 & 2.215 & 0.2725 & 0.2915 \\
2.275 & 0.2317 & 0.2479 & 1.898 & 0.6419 & 0.6868 \\
2.185 & 0.2955 & 0.3162 & 2.027 & 0.4530 & 0.4846 \\
2.032 & 0.4469 & 0.4781 & 1.941 & 0.5715 & 0.6115 \\
2.110 & 0.3619 & 0.3872 & 2.044 & 0.4326 & 0.4629 \\
2.080 & 0.3925 & 0.4200 & 2.004 & 0.4820 & 0.5157 \\
& & & & & \\
& $\mathrm{~V}_{2+}=1.9766$ & $\mathrm{~V}_{3+}=2.1148$ & & $\mathrm{~V}_{2+}=2.85$ & $\mathrm{~V}_{3+}=3.05$
\end{tabular}


Table 5. Kinetics of Se speciation as determined by ITFA/XANES.

\begin{tabular}{cccc}
\multicolumn{4}{c}{$\operatorname{Se}(\mathbf{I}$} \\
$\mathbf{t}(\mathbf{h})$ & $\mathbf{V})$ & $\mathbf{S e}(\mathbf{0})$ & Sum \\
\hline 0.5 & 1.00 & 0.00 & 1.00 \\
1 & 0.95 & 0.06 & 1.01 \\
6 & 0.63 & 0.43 & 1.06 \\
24 & 0.59 & 0.45 & 1.04 \\
96 & 0.56 & 0.50 & 1.06 \\
720 & 0.30 & 0.79 & 1.09 \\
\hline
\end{tabular}



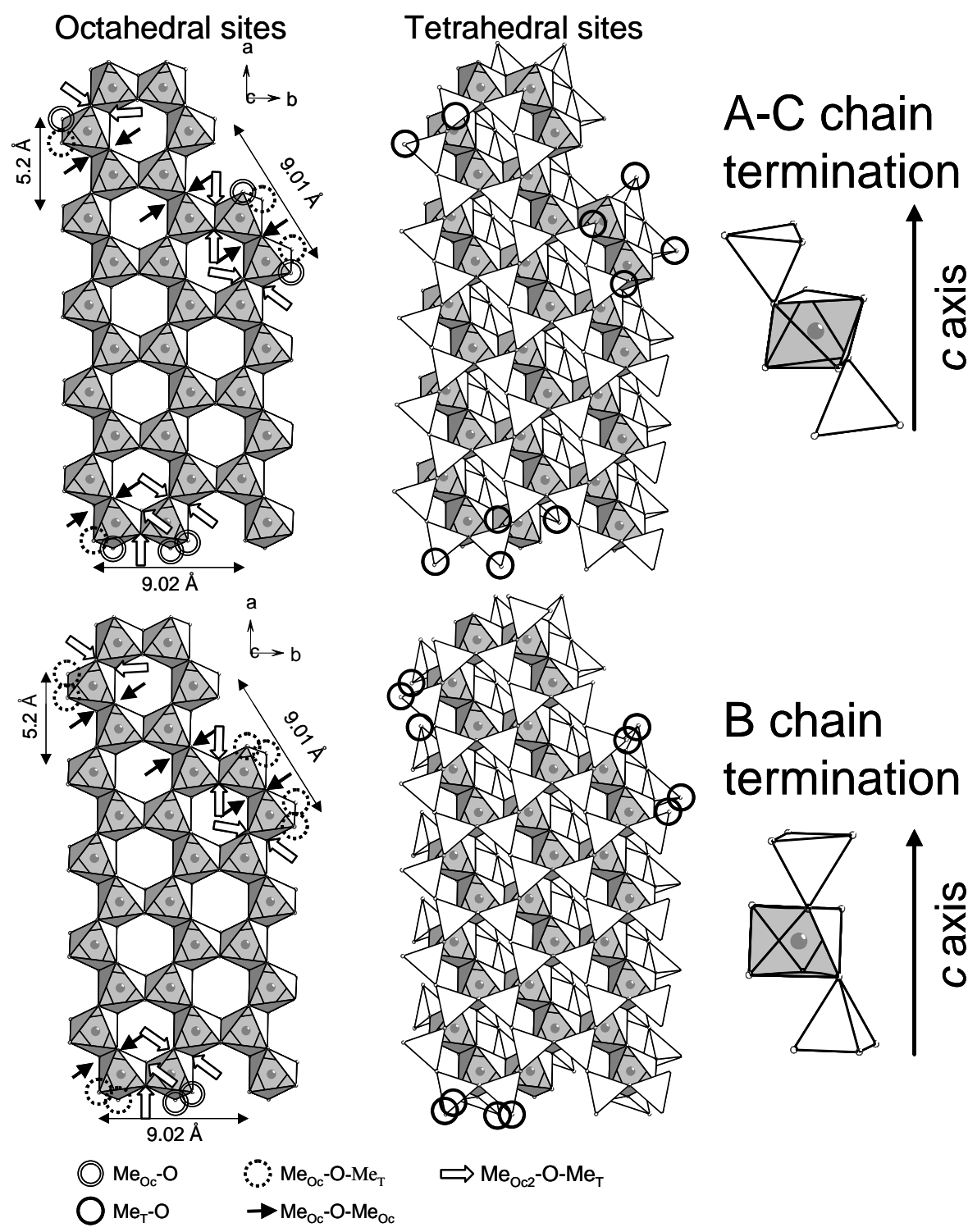

\section{B chain termination}

Fig. 1. Representation of the tetrahedral-octahedral-tetrahedral (TOT) layer structure of montmorillonite. The figures on the left depict only the $\mathrm{Me}(=\mathrm{Al}$, $\mathrm{Mg}$ ) octahedral layer, while those in the middle show the complete TOT layer as seen from above the basal plane. The figures on the right represent the two different types of layer termination (A-C and B type chains after White and Zelazny, 1988). Arrows and circles show different oxygen termination sites coordinated with $\mathrm{Si}, \mathrm{Mg}$ or $\mathrm{Al}$ (from Tournassat et al., 2004b). 

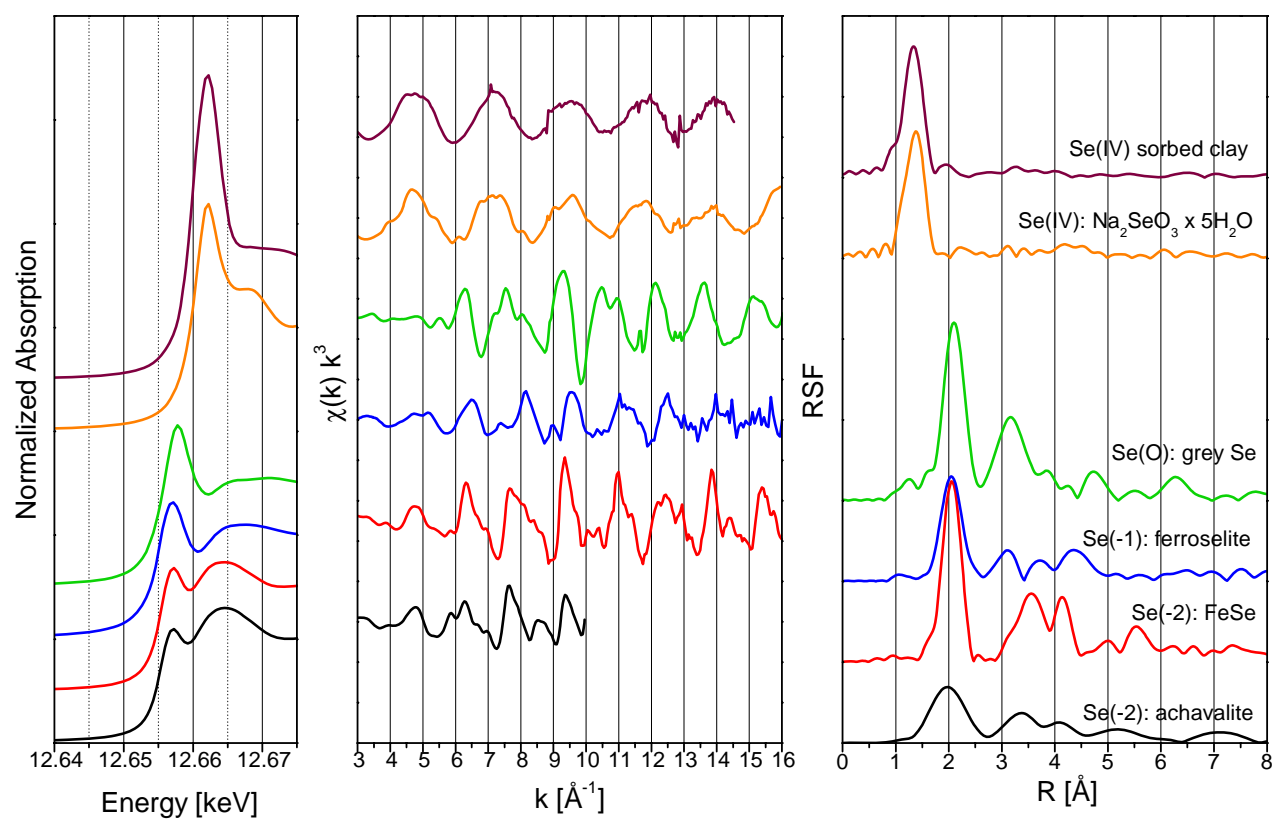

Fig. 2. Selenium K-edge XAS spectra of Se(IV) sorbed to synthetic montmorillonite at $\mathrm{pH} 6.0$ in the absence of $\mathrm{Fe}^{2+}$, in comparison to selected references with $\mathrm{Se}$ oxidation states of IV, 0, -I and -II (left: XANES, center: EXAFS, right: Fourier transform of EXAFS). 


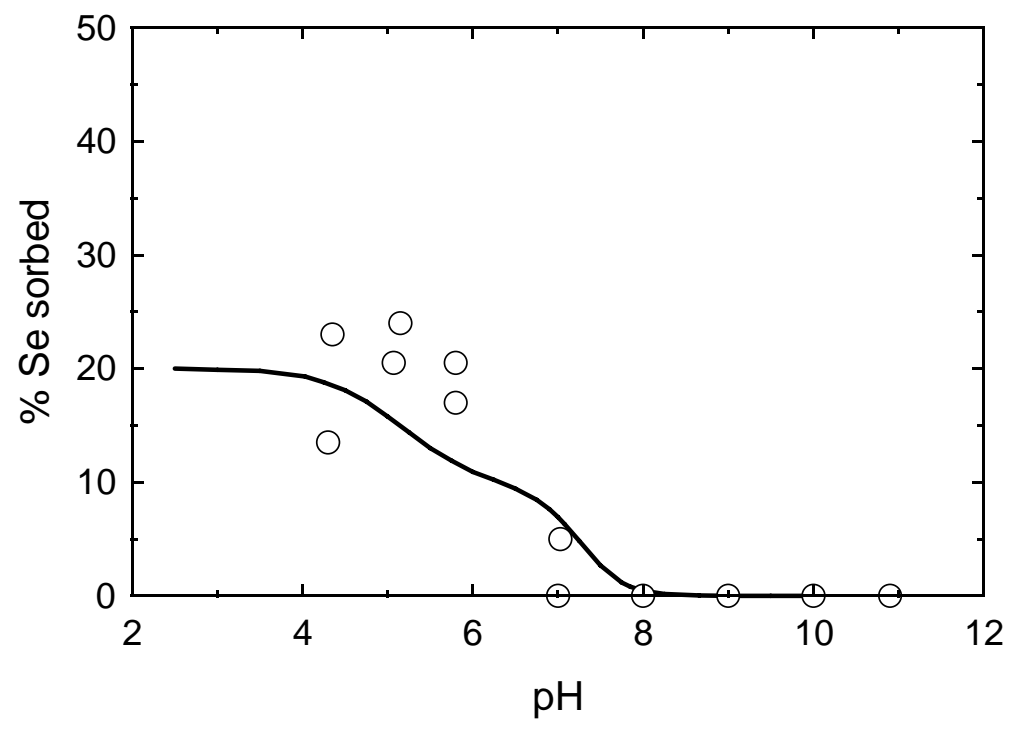

Fig. 3. Sorbed $\mathrm{Se}(\mathrm{IV})$ on purified montmorillonite as a function of $\mathrm{pH}$. Experimental conditions: $20 \mathrm{~g} \mathrm{~L}^{-1}$ clay, $\left[\mathrm{Se}(\mathrm{IV}]=10^{-4} \mathrm{~mol} \mathrm{~L}^{-1}, 0.01 \mathrm{~mol} \mathrm{~L}^{-1} \mathrm{CaCl}_{2}\right.$. Circles: experimental data from Boult et al. (1998); line: our model. 


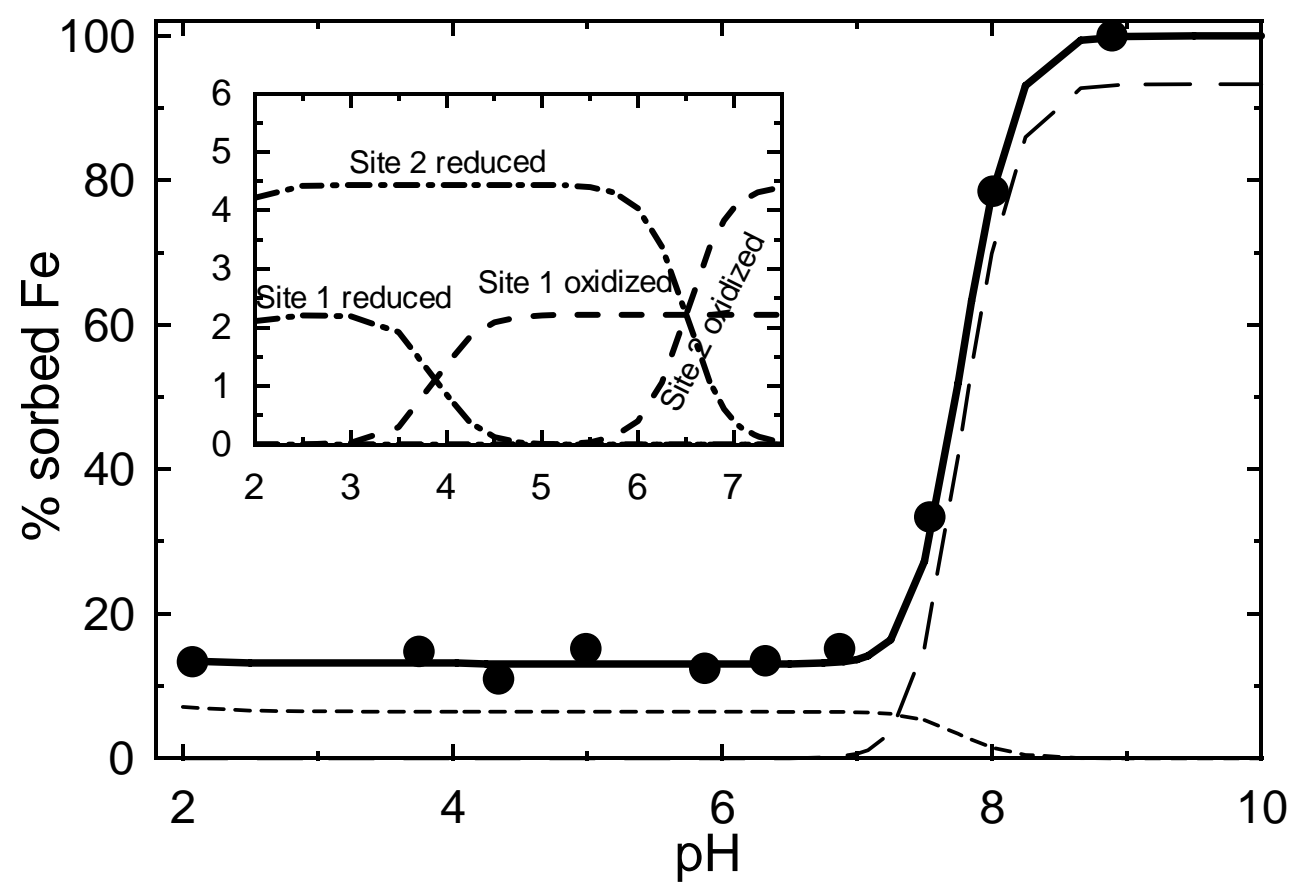

Fig. 4. Sorption of Fe(II) to synthetic montmorillonite (Experimental conditions: 10 $\mathrm{g}_{\text {clay }} \mathrm{L}^{-1},[\mathrm{Fe}(\mathrm{II})]_{\mathrm{t}}=630 \mu \mathrm{M}$ in $\left.0.05 \mathrm{M} \mathrm{CaCl}_{2}\right)$. Closed circles: Fe adsorbed obtained by difference between the total initial $\mathrm{Fe}$ concentration and the equilibrium total $\mathrm{Fe}$ aqueous concentration, measured by ICP-AES. Full line: model total sorbed Fe(II). Short dashed line: cation exchanged $\mathrm{Fe}(\mathrm{II})\left(\mathrm{Fe}^{2+}\right.$ and $\left.\mathrm{FeCl}^{+}\right)$. Long dashed line: $\mathrm{Fe}(\mathrm{II})$ sorbed on weak sites. The insert shows model details in the $\mathrm{pH}<7.5$ range. Dashdotted lines: Fe(II) sorbed on strong sites. Dashed line: Fe(III) sorbed on strong sites.. After Géhin et al., (2007). 


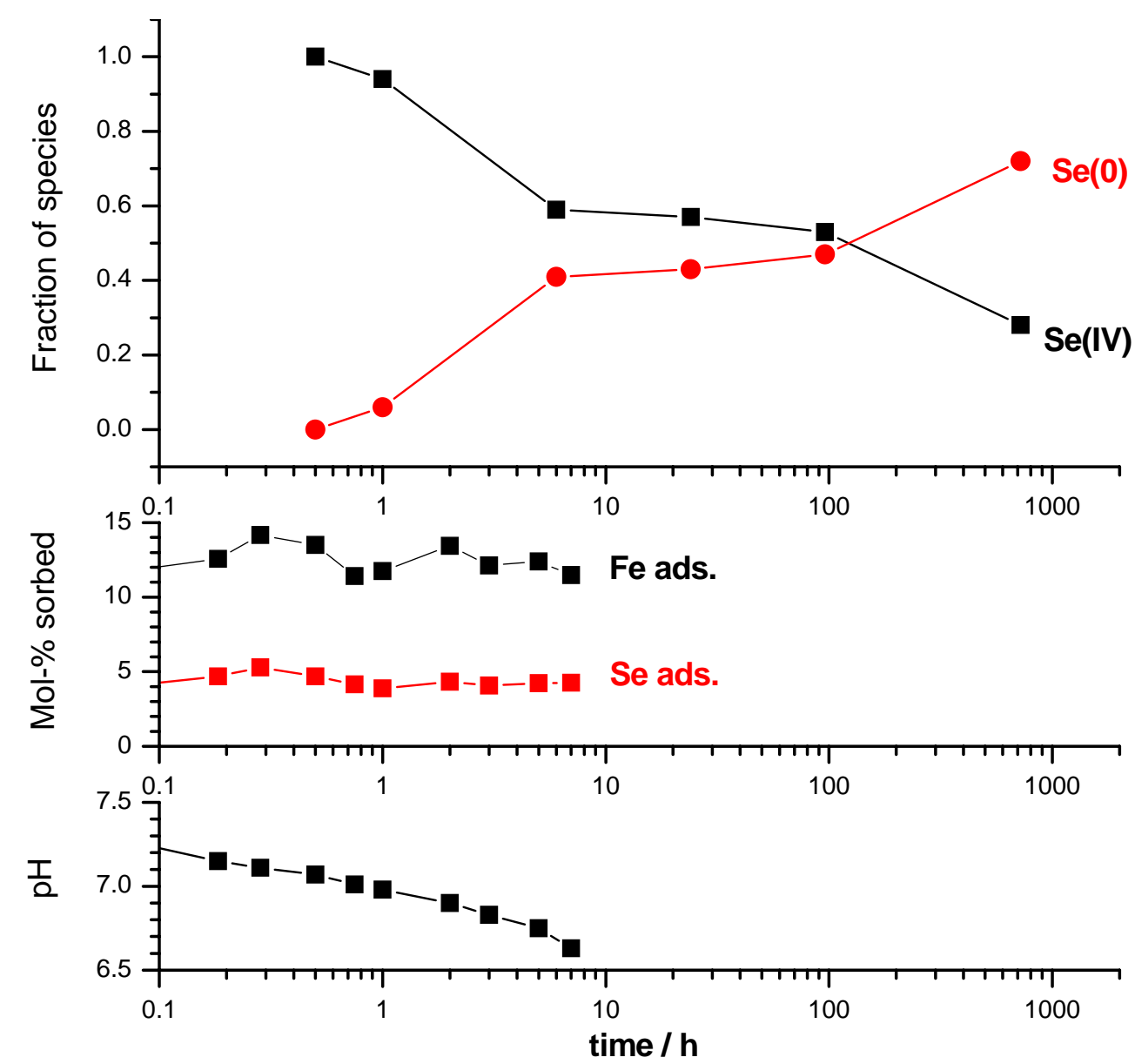

Fig. 5. Kinetics of $\mathrm{Se}(\mathrm{IV})$ reduction at the surface of the $\mathrm{Fe}(\mathrm{II})$-sorbed montmorillonite (Experimental conditions $20 \mathrm{gclay} \mathrm{L}^{-1}, 5 \mathrm{mmol} \mathrm{L}^{-1} \mathrm{Fe}(\mathrm{II}), 0.5 \mathrm{mmol} \mathrm{L}^{-}$ ${ }^{1} \mathrm{Se}(\mathrm{IV}), 0.05 \mathrm{M} \mathrm{CaCl}_{2}$ ). Top: speciation derived from XANES spectra (see Fig. 7, speciation normalized to unity). Center: Percent sorbed Fe and Se. Bottom: $\mathrm{pH}$ 


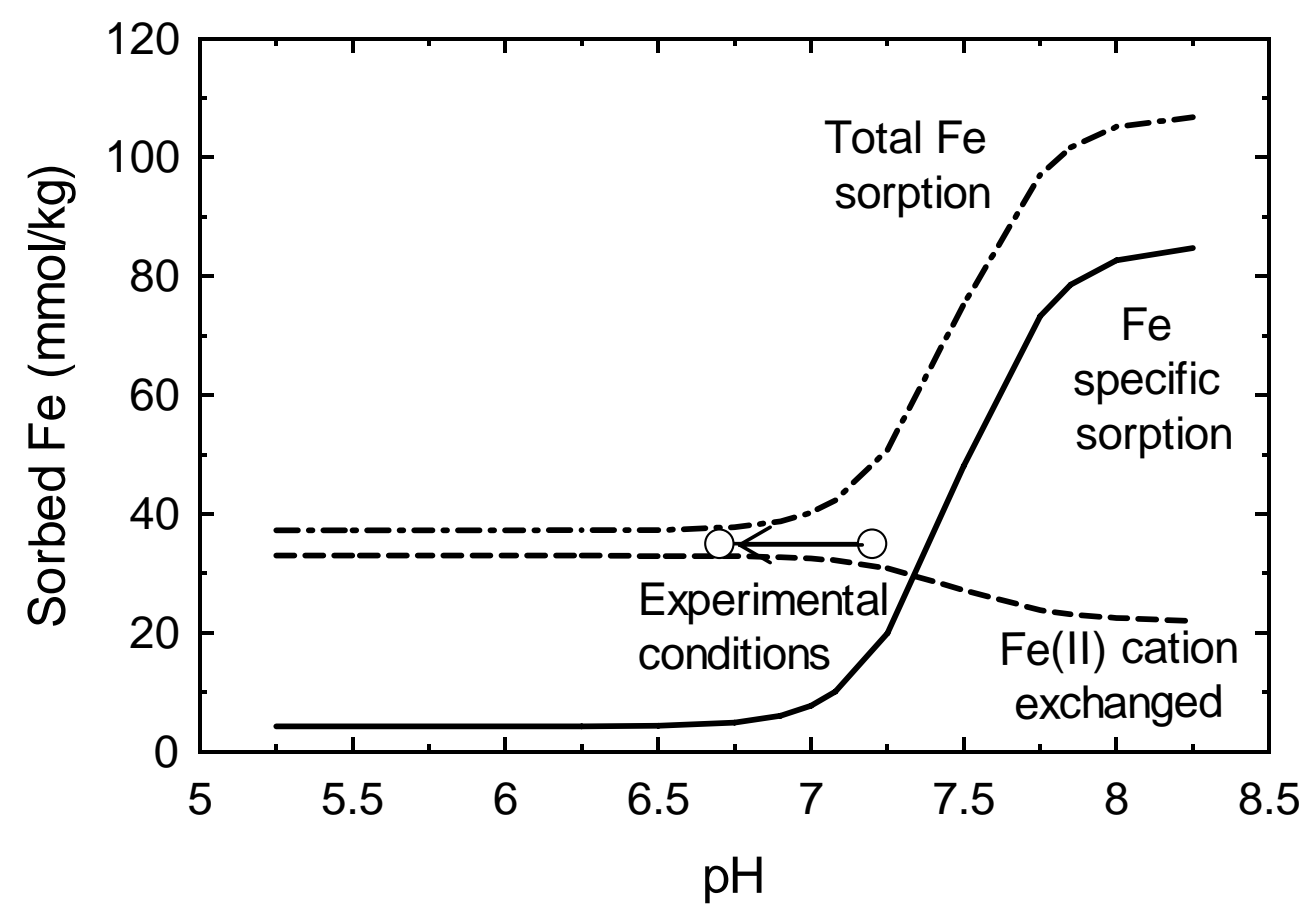

Fig. 6. Modeled Fe sorption by specific sites (full line), and cation exchange sites (dotted line) of synthetic montmorillonite (Experimental conditions: $20 \mathrm{~g}_{\text {clay }} \mathrm{L}^{-1},[\mathrm{Fe}]_{\mathrm{T}}$ $\left.=5 \mathrm{mM},\left[\mathrm{CaCl}_{2}\right]=50 \mathrm{mM}\right)$. Dotted dash line: total sorbed Fe. Symbols: total sorbed $\mathrm{Fe}$ at the beginning and end of the kinetic experiment. 


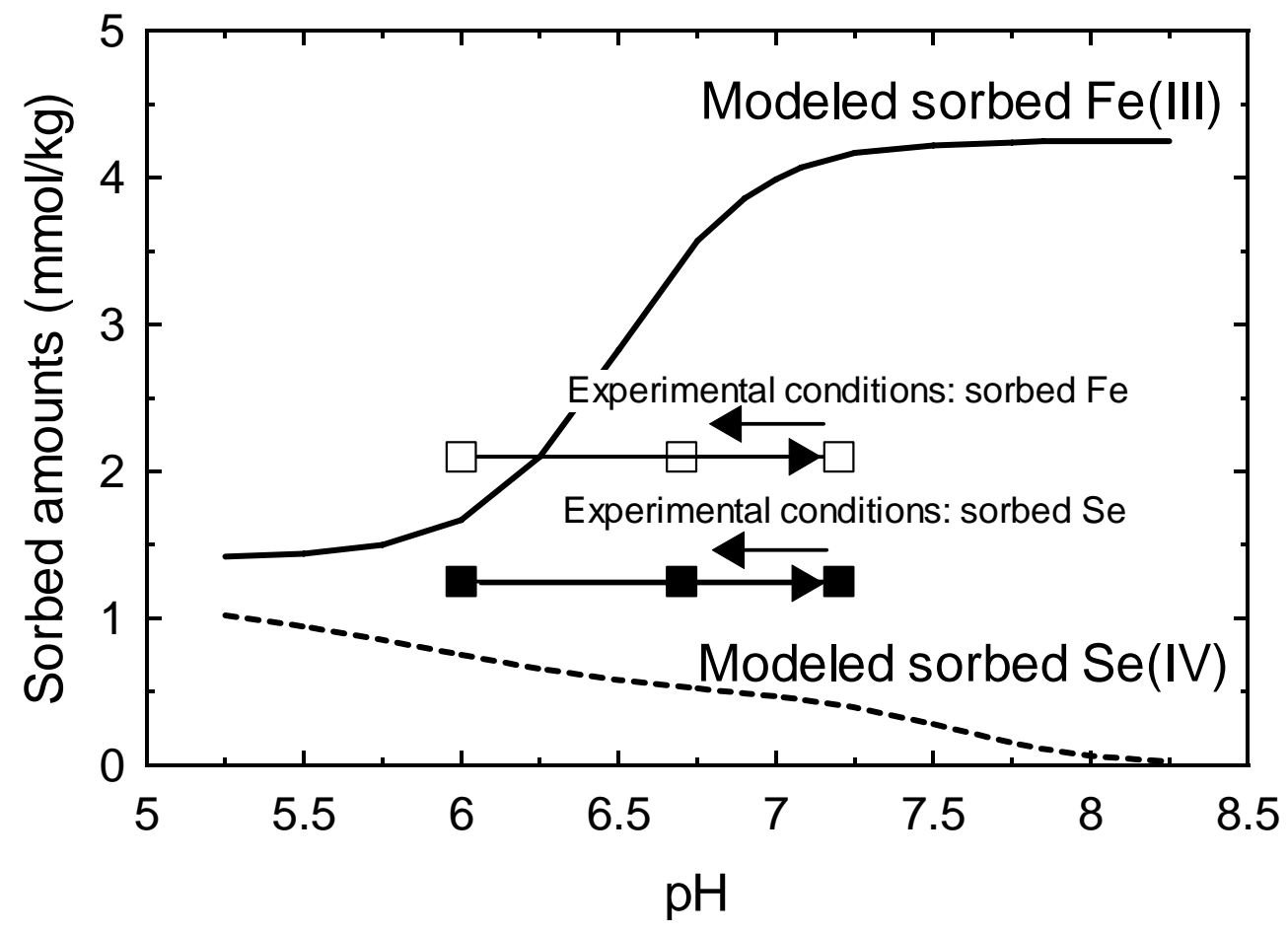

Fig. 7. Modeled Se(IV) sorption on specific sites of synthetic montmorillonite in the absence of Fe and predicted amount of sorbed Fe(III) in the absence of Se after Géhin et al. (2007) (Experimental conditions : $20 \mathrm{~g}_{\text {clay }} \mathrm{L}^{-1},[\mathrm{Fe}]_{\mathrm{T}}=5 \mathrm{mM},\left[\mathrm{CaCl}_{2}\right]=50 \mathrm{mM}$, $[\mathrm{Se}]_{\mathrm{T}}=0.5 \mathrm{mM}$ ). Symbols denote measured sorbed amounts of Se and Fe during the kinetic experiment. 


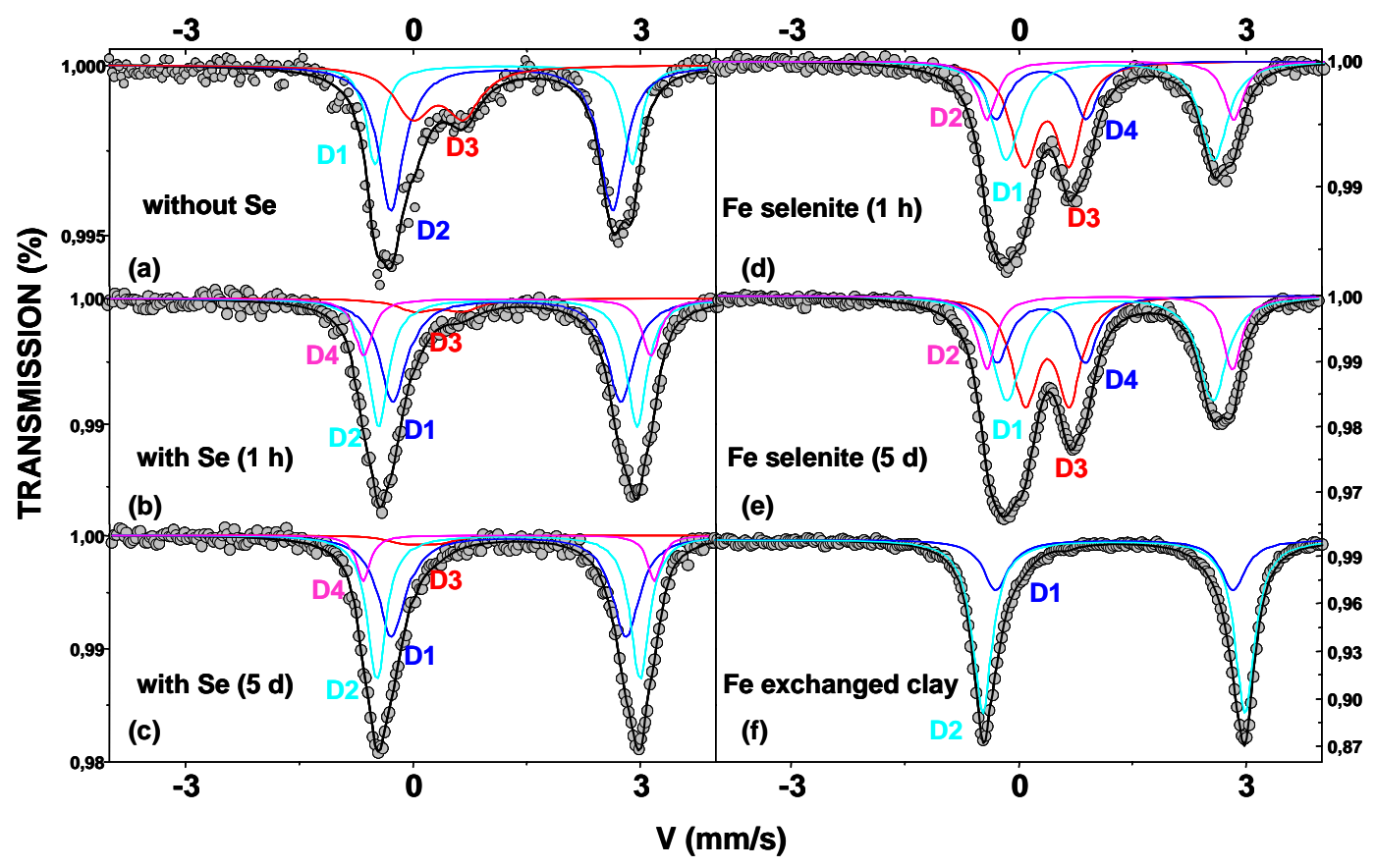

Fig. 8. $77 \mathrm{~K}$ Mössbauer spectra of Fe(II)-sorbed synthetic montmorillonite before (a) and after a 1 hour (b) and a 5 day (c) reaction time with selenite. Spectra (d) and (e) are of an iron selenite precipitate aged for 1 hour and 5 days. Spectrum (f) is of a natural montmorillonite MX80 saturated with a $\sim 0.035 \mathrm{~mol} / \mathrm{L}{ }^{57} \mathrm{FeCl}_{2}$ solution. Spectrum (a) is taken from Géhin et al. (2007), spectrum (f) from Charlet and Tournassat (2005). 


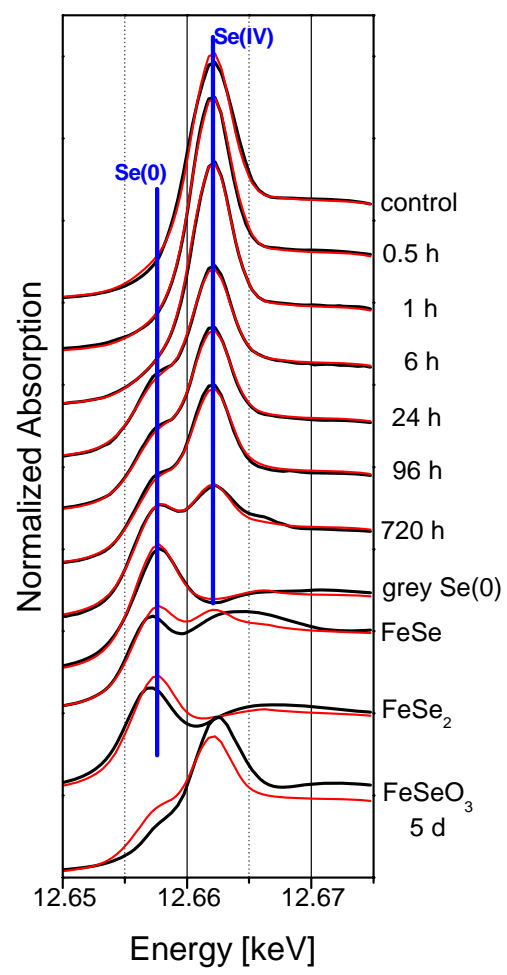

Fig. 9. Se K-edge XANES of $\mathrm{Fe}^{2+}$ clays reacted with $\mathrm{SeO}_{3}{ }^{2-}$ for periods between 0.5 hours and 1 month (black lines) (Experimental conditions $20 \mathrm{~g}_{\text {clay }} \mathrm{L}^{-1}, 5 \mathrm{mmol} \mathrm{L}^{-1}$ $\mathrm{Fe}(\mathrm{II}), 0.5 \mathrm{mmol} \mathrm{L}^{-1} \mathrm{Se}(\mathrm{IV}), 0.05 \mathrm{M} \mathrm{CaCl}_{2}, \mathrm{pH}$ 6). For comparison, the spectra of a $\mathrm{Fe}^{2+}$-free control (top) and of selected reference solids (bottom) are shown. Red lines represent the reconstruction of the spectra with 2 components, extracted from the 7 clay spectra with PCA. Grey $\mathrm{Se}(0)$ is a likely component of the clay spectra, while $\mathrm{FeSe}$ (achavalite), $\mathrm{FeSe}_{2}$ (ferroselite) and the $\mathrm{FeSeO}_{3}$ precipitate are not. 

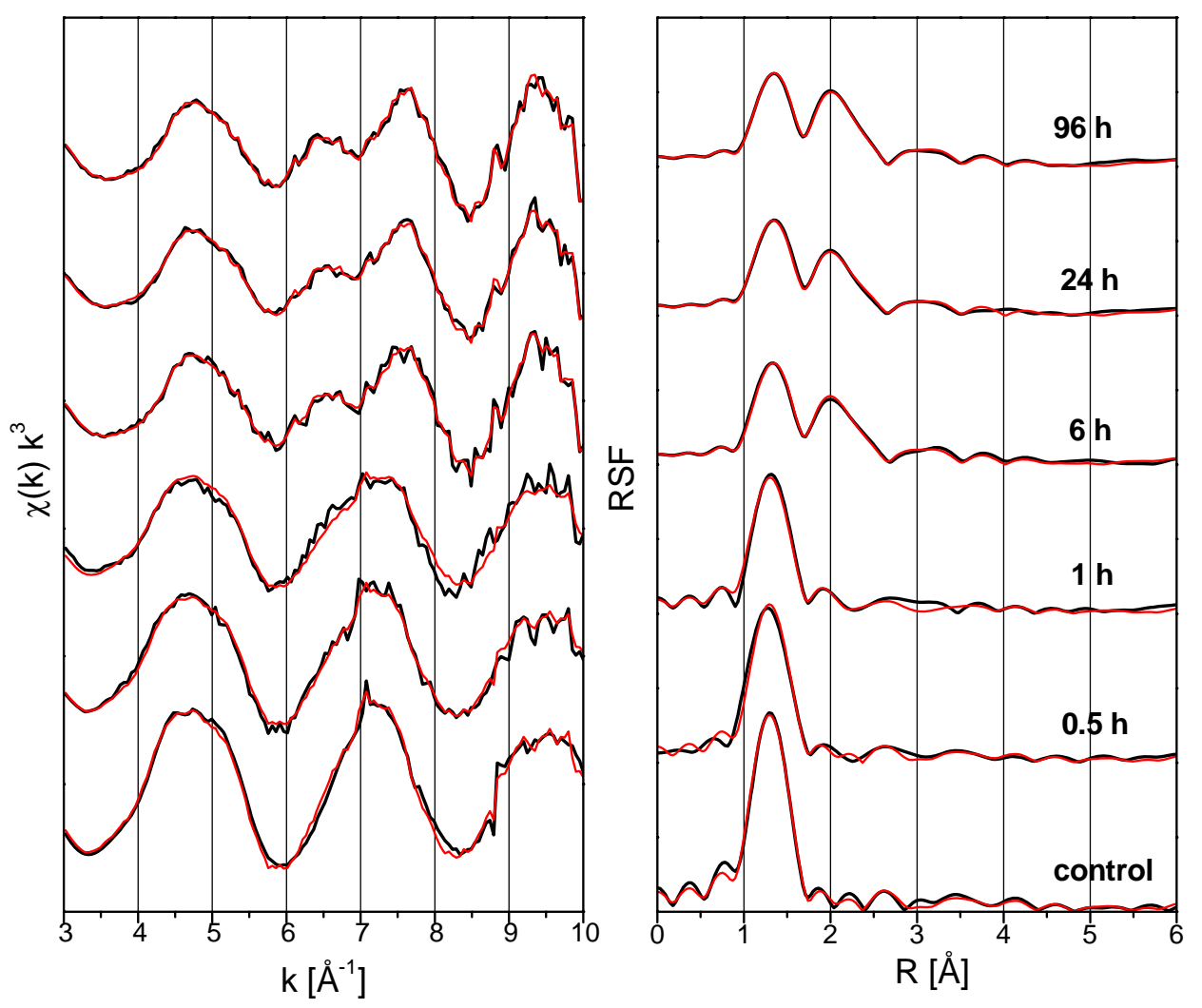

Fig. 10. Se K-edge EXAFS of $\mathrm{Fe}^{2+}$ clays reacted with $\mathrm{SeO}_{3}{ }^{2-}$ for periods between 0.5 hours and 4 days (black lines). For comparison, the spectra of a $\mathrm{Fe}^{2+}$-free control (bottom) is shown. Red lines represent the reconstruction of the spectra with 2 components, extracted from the 6 clay spectra by ITFA. 


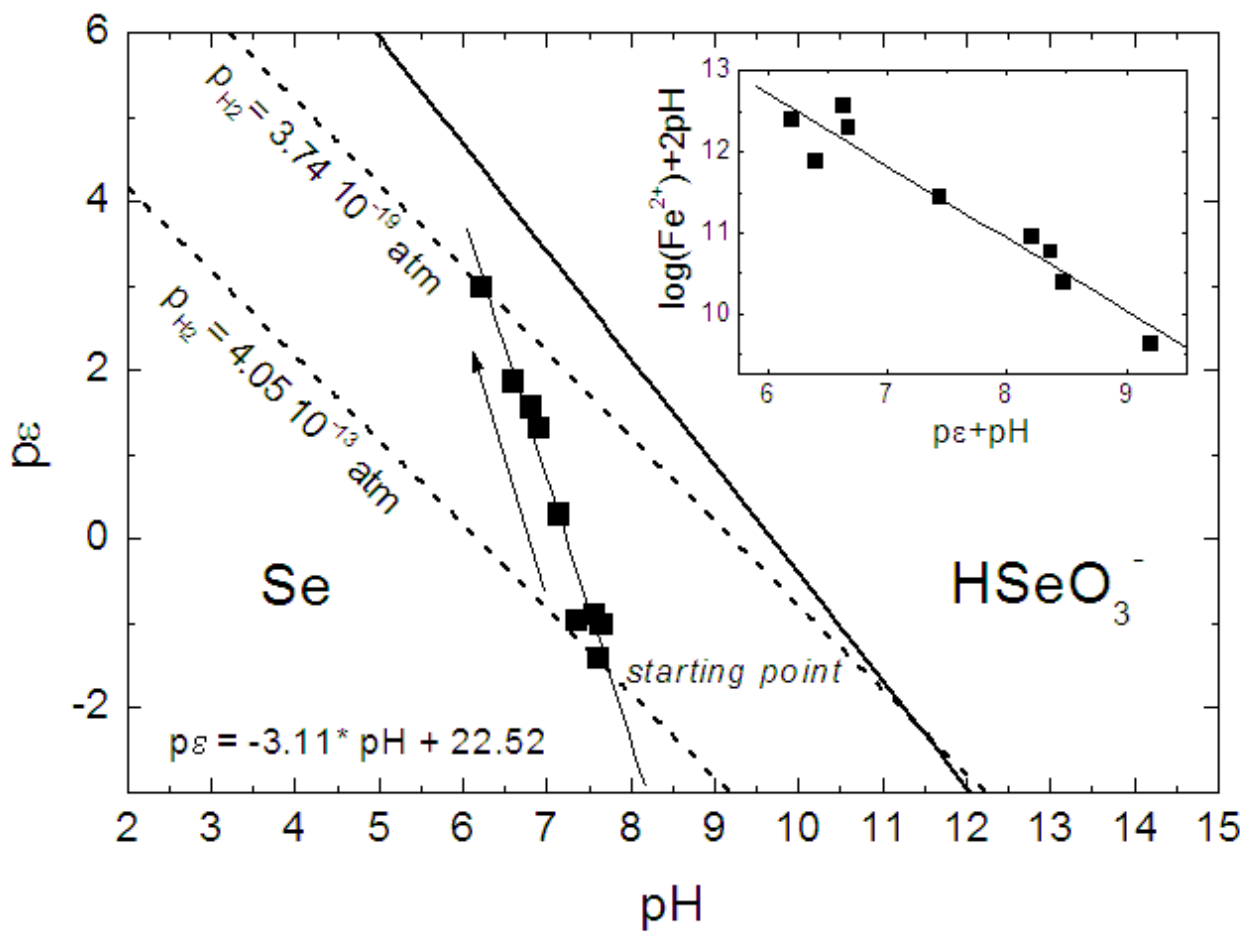

Fig. 11. Solubility diagrams for the system Se-Fe-clay, plotted with kinetic experimental data. The $\mathrm{p} \varepsilon$ - $\mathrm{pH}$ diagram shows the Se stability fields and computed equilibrium $\mathrm{H}_{2} / \mathrm{H}_{2} \mathrm{O}$ lines for two $\mathrm{P}_{\mathrm{H} 2}$ values. 

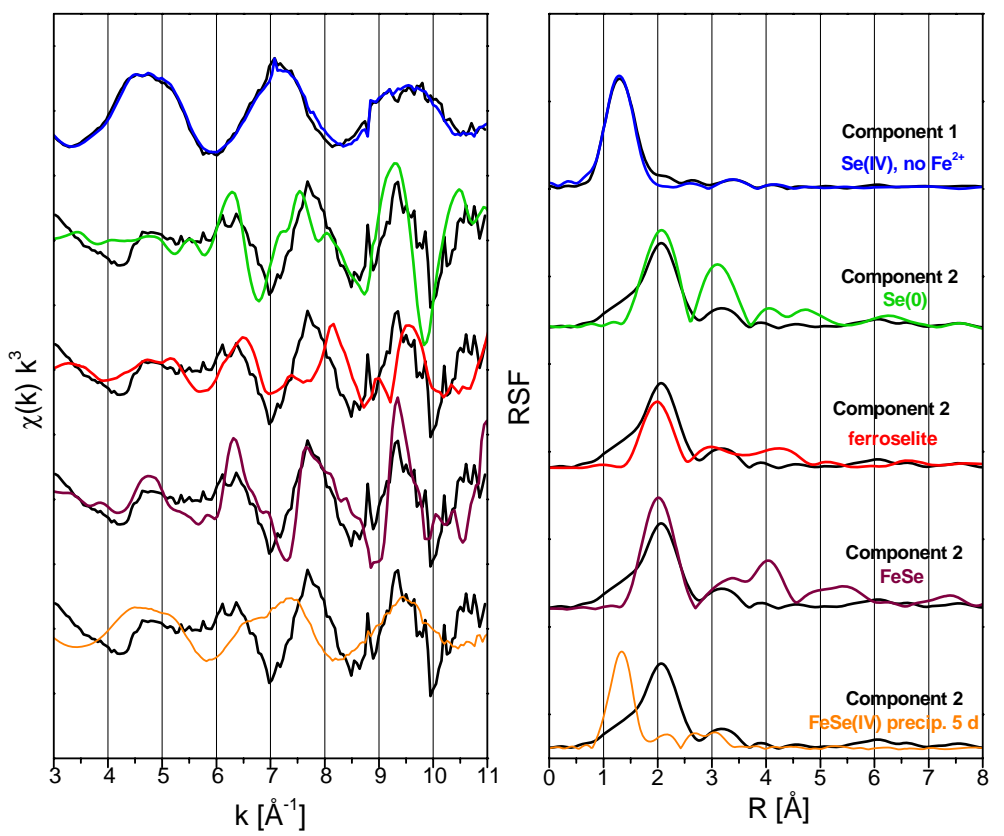

Fig. 12. Extracted spectral components 1 and 2 in comparison to Se K-edge EXAFS spectra of references. 


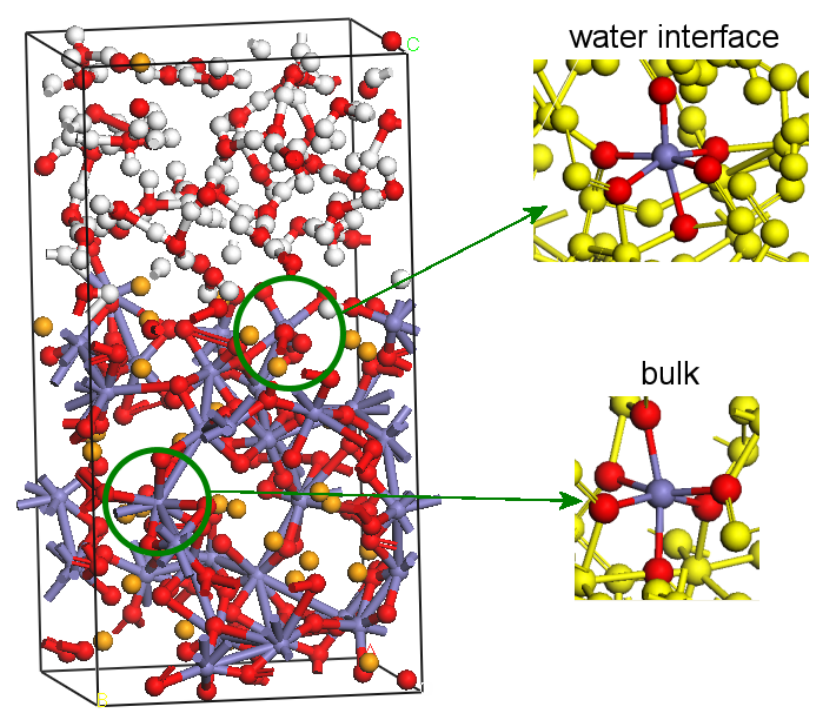

Fig. 13. Simulation box of the $\mathrm{FeSeO}_{3} /$ water interface used in the calculations. The insets show the two different environments for Fe. Octahedral coordination is found in both bulk and interfacial Fe ions. Bond lengths for both Fe sites are shown in Table 4. 